\title{
Chloroplast Genome of Lithocarpus Dealbatus: Identification of Hotspots for Sequence Variability and Phylogeny Analysis in Quercoideae, a Sub-family of Fagaceae
}

\author{
Rahul Shelke \\ CSIR-National Botanical Research Institute \\ Rudra Banerjje \\ CSIR-National Botanical Research Institute \\ Babita Joshi \\ CSIR-National Botanical Research Institute \\ Prem Prakash Singh \\ CSIR-National Botanical Research Institute \\ Gopal Ji Tiwari \\ CSIR-National Botanical Research Institute \\ Dibyendu Adhikari \\ CSIR-National Botanical Research Institute

\section{Satya Narayan Jena} \\ National Botanical Research Institute CSIR \\ Saroj Kanta Barik ( $\sim$ sarojkbarik@gmail.com ) \\ CSIR-National Botanical Research Institute
}

\section{Research Article}

Keywords: Chloroplast, Genome, Lithocarpus dealbatus, Repeat elements, RNA editing, Phylogenetics

Posted Date: February 21st, 2022

DOI: https://doi.org/10.21203/rs.3.rs-1361496/v1

License: @ (1) This work is licensed under a Creative Commons Attribution 4.0 International License. Read Full License 


\section{Abstract}

\section{Background}

There has been phylogenetic ambiguity and species delimitation problem in Lithocarpus genus and the subfamily Quercoideae (Family: Fagaceae). Lithocarpus dealbatus is the dominant genus among the Quercoideae in India. Although several studies have been conducted on regeneration, ecological and economic significance of the species, limited information is available at genome scale. We sequenced and assembled the complete chloroplast genome of $L$. dealbatus and compared with other Quercoideae members to understand the sequence variations, rearrangements and its phylogenetic lineage in the Quercoideae.

\section{Results}

We assembled the 161,476 bp chloroplast genome of L. dealbatus, which has a large single-copy section of $90,732 \mathrm{bp}$ and a small single-copy region of $18,987 \mathrm{bp}$, separated by a pair of inverted repeat regions of 25,879 bp. There were 133 genes in the cp-genome, including 86 protein coding genes, 39 transfer RNAs, and eight ribosomal RNAs. Analysis of repeat elements and RNA editing sites revealed inter-specific similarities within Lithocarpus genus. DNA diversity analysis identified highly diverged coding and non-coding hotspot regions in the genera Lithocarpus, Quercus, Castanea, and Castanopsis. These hot spots can be used as polymorphic barcodes to resolve the phylogenetic relationship at species level. We discovered five barcodes that could aid in species delimitation across the four genera of Quercoideae. The phylogenetic analysis among the Quercoideae established a monophyletic origin of Lithocarpus, and a closer evolutionary lineage with many Quercus species.

\section{Conclusions}

Our findings provide insights into the chloroplast genome of L. dealbatus, the mutational hotspot regions and repeat elements. These could be utilized as molecular markers/barcodes for detailed studies in population genetics.

\section{Background}

Lithocarpus dealbatus (Hook.f. \& Thomson ex Miq.) Rehder., commonly known as stone oak, is a wild nonedible and nut-bearing tree belonging to subfamily Quercoideae under the family Fagaceae. The Quercoideae consists of seven genera viz., Castanea, Castanopsis, Chrysolepis, Lithocarpus, Notholithocarpus, Quercus and Trigonobalanus. The other subfamily Fagoideaeis mono-generic with the genus Fagus. Quercoideae has 10881135 species, while Fagoideae has 11-14 species (The plant list, http://www.theplantlist.org/). Lithocarpus is the second largest genus of the family Fagaceae comprising 330 species (The plant list, http://www.theplantlist.org/), most of which are distributed in the moist/wet evergreen forests of South-East Asia. In India, the genus Lithocarpus is represented by 17 species [1, 2]. L. dealbatus grows at an altitude range of $1,000-1,500 \mathrm{~m}$ asl and attains a height up to $30 \mathrm{~m}[3,4]$. It is found in the subtropical montane forests of the Eastern Himalayas and in the hills of north-eastern India [5]. The species is mostly used as fuelwood and timber, and its fruits (acorns) serve as a food for rodents. The hoarding of acorns by rodents helps the species in wide seed dispersal, maintenance of soil seed bank, and regeneration of the species in the forest [6-11]. 
Lithocarpus is closely related to Quercus, Castanea and Castanopsis genera of Fagaceae [12]. Inter-specific hybridisation within the family often creates ambiguity in species delimitation, thus necessitating to address their complexity in phylogeny [13-15]. The universal plastid markers cannot provide sufficient number of variable sites and phylogenetic signals to investigate the phylogeny in Quercoidaeae [16-18]. Previously, the use of nuclear markers in Fagaceae phylogeny inference yielded relatively low support for the monophyletic genus Quercus [18]. The results of earlier workers have showed that a single marker or even a combination of markers has very low discrimination rate [17]. Therefore, the chloroplast genome has been successfully used for phylogenetic analysis in Castanea and Castanopsis to resolve taxonomic discrepancies [16]. Chloroplast genome sequences have been widely used to resolve plant phylogenies due to their highly conserved structure and recombination-free uniparental inheritance [16]. In Quercus, Pang et al. [17] emphasized the species-level discrimination and the improvement of the phylogenetic resolution by using chloroplast genome sequences.

The chloroplast genome sequences have been also used to identify the mutational hot spot regions for designing the species-specific DNA barcodes. Unlike universal barcodes, the mutational hotspots can far better differentiate plant taxa down to the species level $[15,16]$. Previously, Pang et al. [17] demonstrated that the newly discovered markers were more variable than the standard and universal plant DNA markers in Quercus species (e.g. rbcL and matK). Extremely low resolution of universal DNA barcode was also reported in the 12 Italian oak species [19]. As a result, several reports have been published highlighting the need to develop additional barcodes in Quercoidaeae species $[17,20]$. Researchers have demonstrated that chloroplast genome mutations are clustered into hotspots, and these hotspot regions can be considered as real DNA barcodes [21]. Following the approach of mutational hotspots from the entire chloroplast genome, the species-specific barcodes in oak and Castanea species have been designed $[17,20]$. Despite the fact that some specific barcodes with the highest discriminatory power have previously been reported in Quercus, additional markers are still required for the rest of the Quercoidaeae species considering their complex evolutionary background. Therefore, the availability of genomic information is essential to understand the evolutionary relationship of Lithocarpus genus and its species with other genera of Fagaceae.

Plant chloroplast genomes have circular quadripartite structure with sizes ranging from 107 to $218 \mathrm{~kb}$ [21]. In terms of structural organisation, gene content and layout, the chloroplast genome is extremely conserved [25]. Small single-copy (SSC) and large single-copy (LSC) sections are separated by two inverted repeats (IR) regions in the genome [25]. The chloroplast has 130 genes, including 80 protein-coding genes, 4 rRNA genes, and 35 tRNA genes [19]. The chloroplast genome is uniparentally inherited and highly conserved in nature, thus accumulating slow rate of evolutionary changes [22-26]. Despite the overall structural conservation, and contraction and expansion of the IR boundaries, the chloroplast genome can lead to variations in gene content resulting in genome size variation [27]. Besides, several mutational events happen in the genome due to insertion or deletion, single nucleotide polymorphisms (SNP), simple sequence repeats (SSRs) and tandem repeats $[27,28]$. Such genome-scale variations open up the possibility of using these regions as molecular markers in diversity research, population genetics, and phylogenetic investigations [29-31]. To address the limited resolution of single-locus DNA barcodes, the entire chloroplast genome has recently been employed to obtain more reliable evolutionary evidence [30,32].

In recent times, the advancement of high throughput sequencing technologies resulted in increase in chloroplast genomes in the public domain. However, genomic information on Lithocarpus, particularly complete chloroplast 
genome in the NCBI database is represented by only two species [33];https://www.ncbi.nlm.nih.gov/nuccore/? term=Lithocarpus+chloroplast\%2C+complete+genome). Therefore, in the present study, we sequenced and assembled the complete chloroplast genome of $L$. dealbatus. The assembled chloroplast genome was successfully annotated and compared with other Quercoideae members to understand its structural variations and rearrangements. In addition, a phylogenetic tree was constructed to deduce the evolutionary relatedness of L. dealbatus with other members of Quercoideae clade. The highly divergent regions and the SSRs identified in the chloroplast genome will improve the understanding of the ecological significance with reference to its spatial distribution, adaptability, and evolutionary relationship of $L$. dealbatus within Fagaceae.

\section{Results}

\section{L. dealbatus chloroplast genome assembly and structure}

A total of $\sim 47 \mathrm{~Gb}$ data with more than 15,67,18,852 adapter clean short PE reads were used for de novo chloroplast genome assembly. The total length of the assembled $L$. dealbatus chloroplast genome was 161,476 bp with an average coverage of $1494 \times$ (Fig. 1). The complete chloroplast genome exhibits a typical quadripartite structure, comprising a pair of IR (IRA and IRB) regions ( $25,879 \mathrm{bp})$ divided by an SSC region $(18,987 \mathrm{bp})$ and an LSC region (90,732 bp). The overall GC content of the genome was $36.7 \%$, while the GC content of LSC, SSC and IR regions were $34.6 \%, 30.9 \%$ and $42.7 \%$, respectively.

Homology searched through the BLASTN program revealed a high sequence similarity of $L$. dealbatus Chloroplast genome with Lithocarpus hancei and Lithocarpus balansae Chloroplast genome. A high-quality chloroplast genome sequence was finally submitted to the Genbank, NCBI database under the accession number MZ322408.

\section{Chloroplast genome encoding genes}

The whole chloroplast genome of L. dealbatus encodes 133 genes, consisting of 86 protein-coding genes, 39 transfer RNA (tRNA) and 8 ribosomal RNA (rRNA) genes (Table 1). Among 133 genes, eight protein-coding genes ( $n d h B, p s b D, r p / 2, r p / 23, r p s 7, r p s 12, y c f 1$ and $y c f 2$ ), nine tRNA and four RNA genes were duplicated in the genome (Table 2). Altogether, 13 protein-coding and eight tRNA genes were found to contain an intron, in which two genes ( $y c f 3$ and $c l p P)$ harboured double intron. The rps12 was identified as a trans-spliced gene in the genome. However, trnk-UUU has an intron encompassing the matK gene. The IR regions each harboured seven protein-coding genes, seven tRNA and four rRNAs. 
Table 1

Details list of genes encoded by $L$. dealbatus chloroplast genome

\begin{tabular}{|c|c|c|c|c|c|}
\hline \multirow{2}{*}{$\begin{array}{l}\text { Gene category } \\
\text { Ribosomal RNA genes }\end{array}$} & \multicolumn{5}{|c|}{ Gene name } \\
\hline & $\operatorname{rrn} 16^{D}$ & $\operatorname{rrn} 23^{D}$ & $\operatorname{rrn} 4.5^{D}$ & $r r n 5^{D}$ & \\
\hline \multirow[t]{6}{*}{ Transfer RNA genes } & $\begin{array}{l}\operatorname{trn} A-U G C \\
D^{*}\end{array}$ & $\operatorname{trn} C-G C A$ & $\begin{array}{l}\operatorname{trn} D- \\
\text { GUC }\end{array}$ & $\begin{array}{l}\text { trnE- } \\
\text { UUC }\end{array}$ & $\begin{array}{l}\operatorname{trn} F- \\
G A A\end{array}$ \\
\hline & $\begin{array}{l}\text { trnfM- } \\
C A U\end{array}$ & $\operatorname{trn}_{D^{*}}$ & $\begin{array}{l}\operatorname{trnH} H- \\
G U G\end{array}$ & $\begin{array}{l}\text { trnl- } \\
C A U^{D}\end{array}$ & $\begin{array}{l}\operatorname{trnl-GAU} \\
D^{*}\end{array}$ \\
\hline & $\underset{*}{\operatorname{trn} K-U U U}$ & $\begin{array}{l}\operatorname{trn} L-C A A \\
D\end{array}$ & $\begin{array}{l}\operatorname{trn} L- \\
U A A^{*}\end{array}$ & $\begin{array}{l}\operatorname{trnL}- \\
U A G\end{array}$ & $\begin{array}{l}\text { trnM- } \\
C A U\end{array}$ \\
\hline & $\begin{array}{l}\operatorname{trn} N-G U U \\
D\end{array}$ & $\operatorname{trnP-GGG}$ & $\begin{array}{l}\operatorname{trn} P- \\
U G G\end{array}$ & $\begin{array}{l}\operatorname{trnQ-} \\
U U G\end{array}$ & $\begin{array}{l}\operatorname{trnR} R^{-} \\
A C G^{D}\end{array}$ \\
\hline & $\operatorname{trnR} R-U C U$ & $\operatorname{trnS-GCU}$ & $\begin{array}{l}\operatorname{trnS}- \\
G G A\end{array}$ & $\begin{array}{l}\operatorname{trnS}- \\
U G A\end{array}$ & $\begin{array}{l}\operatorname{trn} T- \\
G G U^{D}\end{array}$ \\
\hline & $\operatorname{trnT-UGU}$ & $\begin{array}{l}\operatorname{trn} V-G A C \\
D\end{array}$ & $\begin{array}{l}\operatorname{trn} V- \\
U A C^{*}\end{array}$ & $\begin{array}{l}\operatorname{trn} W- \\
C C A\end{array}$ & $\begin{array}{l}\operatorname{trn} Y- \\
G U A\end{array}$ \\
\hline \multirow[t]{2}{*}{ Large subunit of ribosomal proteins (LSU) } & $r p / 2^{D^{*}}$ & rp/14 & $r p / 16$ & rp/20 & rp/22 \\
\hline & $r p / 23^{D}$ & rp/32 & rp/33 & rp/36 & \\
\hline \multirow[t]{3}{*}{ Small subunit of ribosomal proteins (SSU) } & rps2 & rps3 & rps4 & $r p s 7^{D}$ & rps8 \\
\hline & rps11 & $\operatorname{rps} 12^{D^{*}}$ & rps14 & rps15 & $\operatorname{rps} 16^{*}$ \\
\hline & rps18 & rps19 & & & \\
\hline DNA dependant RNA polymerase & rpoA & $r p o B$ & rpoc1 * & rpoc2 & \\
\hline Photosystem I & $\operatorname{psaA}$ & psaB & psaC & psal & psaJ \\
\hline \multirow[t]{3}{*}{ Photosystem II } & $p s b A$ & $p s b B$ & $p s b C$ & $p s b D^{D}$ & $p s b E$ \\
\hline & $p s b F$ & psbH & psbl & psbJ & psbK \\
\hline & $p s b L$ & psbM & $p s b N$ & $p s b T$ & $p s b Z$ \\
\hline \multirow[t]{2}{*}{ Cytochrome b/f } & petA & petB * & petD & petG & petL \\
\hline & $\operatorname{petN}$ & & & & \\
\hline ATP synthase & $\operatorname{atp} A$ & $\operatorname{atp} B$ & atpE & $\operatorname{atp} F^{*}$ & atpH \\
\hline \multicolumn{6}{|l|}{$\nabla$ Genes with one intron. } \\
\hline \multicolumn{6}{|l|}{ 怄 Gene containg two introns. } \\
\hline ed copies. & & & & & \\
\hline
\end{tabular}




\begin{tabular}{|c|c|c|c|c|c|}
\hline Gene category & Gene $\mathrm{n}$ & & & & \\
\hline & atpl & & & & \\
\hline Protease & $c l p P^{* *}$ & & & & \\
\hline Rubisco & $r b c L$ & & & & \\
\hline NADH dehydrogenase & $n d h A^{*}$ & $n d h B^{D^{*}}$ & $n d h C$ & $n d h D$ & $n d h E$ \\
\hline & $n d h F$ & $n d h G$ & $n d h H$ & $n d h l$ & $n d h J$ \\
\hline & $n d h K$ & & & & \\
\hline Maturase & matK & & & & \\
\hline Envelop membrane protein & cemA & & & & \\
\hline Subunit of acetyl-CoA-carboxylase & $a c c D$ & & & & \\
\hline C-type cytochrome synthesis gene & $\operatorname{ccs} A$ & & & & \\
\hline $\begin{array}{l}\text { Conserved hypothetical chloroplast open } \\
\text { reading frames }\end{array}$ & $y c f 7^{D}$ & $y c f 2^{D}$ & $y c f 3^{* *}$ & $y c f 4$ & \\
\hline$\nabla$ Genes with one intron. & & & & & \\
\hline $\mathbb{Q}$ Gene containg two introns. & & & & & \\
\hline D Gene harbouring duplicated copies. & & & & & \\
\hline
\end{tabular}


Table 2

Comparative analysis of seven Quercoideae chloroplast genomes.

\begin{tabular}{|c|c|c|c|c|c|c|c|}
\hline Species & $\begin{array}{l}\text { L. } \\
\text { dealbatus }\end{array}$ & $\begin{array}{l}\text { L. } \\
\text { balansae }\end{array}$ & L. & $\begin{array}{l}\text { C. } \\
\text { henryi }\end{array}$ & C. sclerophylla & $\begin{array}{l}\text { Q. } \\
\text { pannosa }\end{array}$ & $\begin{array}{l}T \text { doichangensis } \\
\text { dis }\end{array}$ \\
\hline $\begin{array}{l}\text { Genome } \\
\text { size }\end{array}$ & $\begin{array}{l}161,476 \\
\mathrm{bp}\end{array}$ & $\begin{array}{l}161,020 \\
\mathrm{bp}\end{array}$ & $\begin{array}{l}161,304 \\
\mathrm{bp}\end{array}$ & $\begin{array}{l}160,907 \\
\mathrm{bp}\end{array}$ & $160,497 \mathrm{bp}$ & $\begin{array}{l}161,222 \\
\mathrm{bp}\end{array}$ & $159,938 \mathrm{bp}$ \\
\hline LSC & 90,732 bp & $\begin{array}{l}90,596 \\
\mathrm{bp}\end{array}$ & $\begin{array}{l}90,585 \\
\mathrm{bp}\end{array}$ & $\begin{array}{l}90,527 \\
\mathrm{bp}\end{array}$ & $90,255 \mathrm{bp}$ & $\begin{array}{l}90,522 \\
\mathrm{bp}\end{array}$ & 89,445 bp \\
\hline ssc & 18,987 bp & $\begin{array}{l}19,160 \\
b p\end{array}$ & $\begin{array}{l}18,959 \\
\mathrm{bp}\end{array}$ & $\begin{array}{l}18,998 \\
\mathrm{bp}\end{array}$ & $25,675 \mathrm{bp}$ & $\begin{array}{l}19,000 \\
\mathrm{bp}\end{array}$ & 19,295 bp \\
\hline IR & $25,879 \mathrm{bp}$ & $\begin{array}{l}25,632 \\
\mathrm{bp}\end{array}$ & $\begin{array}{l}25,880 \\
\mathrm{bp}\end{array}$ & $\begin{array}{l}25,961 \\
\mathrm{bp}\end{array}$ & 18,892 bp & $\begin{array}{l}25,850 \\
\mathrm{bp}\end{array}$ & $25,600 \mathrm{bp}$ \\
\hline $\begin{array}{l}\text { Protein } \\
\text { coding } \\
\text { genes }\end{array}$ & 86 & 87 & 87 & 82 & 86 & 85 & 81 \\
\hline rRNAs & 8 & 8 & 8 & 8 & 8 & 8 & 8 \\
\hline tRNAs & 39 & 39 & 44 & 37 & 37 & 37 & 39 \\
\hline $\begin{array}{l}\text { Duplicated } \\
\text { genes }\end{array}$ & 21 & 19 & 24 & 17 & 21 & 17 & 17 \\
\hline CDS & 80,577 bp & $\begin{array}{l}80,142 \\
b p\end{array}$ & $\begin{array}{l}80,199 \\
\text { bp }\end{array}$ & $\begin{array}{l}77,685 \\
\mathrm{bp}\end{array}$ & 79,647 bp & $\begin{array}{l}78,852 \\
\mathrm{bp}\end{array}$ & 71,778 bp \\
\hline NCDS & 80,899 bp & $\begin{array}{l}80,878 \\
b p\end{array}$ & $\begin{array}{l}81,105 \\
\mathrm{bp}\end{array}$ & $\begin{array}{l}83,222 \\
\mathrm{bp}\end{array}$ & $80,850 \mathrm{bp}$ & $\begin{array}{l}82,370 \\
\mathrm{bp}\end{array}$ & $88,360 \mathrm{bp}$ \\
\hline GC\% & 36.7 & 36.7 & 36.7 & 36.7 & 36.8 & 36.9 & 37 \\
\hline \multicolumn{8}{|c|}{ CDS - coding sequence. } \\
\hline NCDS - N & a & & & & & & \\
\hline
\end{tabular}

\section{Comparison of Quercoideae chloroplast genomes}

Mauve alignment identified four locally collinear blocks in L. dealbatus and other six were compared with publicly available genomes (Fig. 2). Overall, the synteny of gene order was similar in all genomes except an inversion of around $275 \mathrm{bp}$ in the LSC region of $T$. diochangensis (Figure S1). The inversion has explicitly occurred in the intronic region of the atpF gene. The mVista genome alignment showed that the genic regions were mostly conserved with a few exceptions (Fig. 3). Overall, the Lithocarpus genome showed a higher level of nucleotide identity in comparison to Castenea, Castinopsis and Quercus. In the present investigation, ycf1 gene revealed significant variation among the seven compared genomes. Intronic regions revealed a higher level of divergence in contrast to the un-translated region (UTR) and genic regions.

The size variation in chloroplast genomes is often due to the expansion and contraction of IR junctions in higher plants. Hence, we analysed and compared the location of the IR border and their adjacent genes among 
the compared chloroplast genomes (Fig. 4). In L. dealbatus, the ycf1 gene was detected at IRB/SSC junction with $4607 \mathrm{bp}$ inside SSC and $1083 \mathrm{bp}$ inside the IRB region. On the other hand, the other partially duplicated copy of the ycf1 gene was found at IRA/SSC junction with 1083 bp inside IRA and 20 bp inside the SSC region. A similar trend was observed in all the compared genomes except in Quercus pannosa and T. diochangensis, where $y c f 1$ was missing at IRA/SSC or IRB/SSC junctions. The size of the $y c f 1$ gene in L. dealbatus ranged from $1103 \mathrm{bp}$ to $5690 \mathrm{bp}$. Conversely, the length of $y c f 1$ gene in the rest of the genomes varied between $795 \mathrm{bp}$ in T. diochangensis and 5681 bp in Q. pannosa genome. The $n d h F$ gene was positioned near IRA/SSC region in the compared genomes except that in T. diochangensis. Besides, ycf1 overlapped with the $n d h F$ gene at IRA/SSC junctions in three genomes such as L. hancei, Castanopsis sclerophylla and Castanea henryi. Two genes, $r p s 19$ and $r p / 2$ were spotted completely inside the LSC and IRB regions on either side of the IRB/LSC junction. Other duplicated copy of $r p / 2$ gene was situated entirely inside the IRA region and was only absent in $T$. diochangensis. We observed the position of $\mathrm{trnH}$ gene within LSC region in all the seven compared genomes.

\section{Repeat sequences}

The chloroplast genome of $L$. dealbatus comprised 43 repeat regions, of which 17 were forward, 22 were palindromic, 3 were reverse, and one was a compliment (Fig. 5A, B). Overall, the total number of tandem repeats varied between 34 in Q. pannosa and 49 in Trigonobalanus doichangensis (Fig. 5A). Comparative analysis showed that most repeats were palindromic, ranging from 19-26 in numbers in seven compared genomes (Fig. 5B). This was followed by forward repeats with the highest number in $C$. henryi(19) and lowest in $C$. sclerophylla and Q. pannosa, each with 12 repeats. The reverse repeats were absent in C.sclerophylla, while these were highest in $L$. hancei and $T$. doichangensis (5). Similarly, a limited number of complement repeats were observed in L. hancei (2), C. henryi (1) and C. sclerophylla (2), whereas it was absent in L. balansae, Q. pannosa and $T$. doichangensis. The majority of the repeats ranged from $30-34 \mathrm{bp}$, while a negligible number of repeats belonged to the size category of 45-64bp (Fig. 5C).

We also mined 125 simple and 30 compound SSRs in the chloroplast genome of $L$. dealbatus (Fig. 6A). Among 125 simple SSRs, 83 were mono- nucleotides (66.4\%), 18 were di- nucleotides $(14.4 \%), 8$ were tri- nucleotides $(6.4 \%)$, and 10 were tetra-nucleotides (8\%). Besides, the number of penta-nucleotides was only 5 (4\%), followed by a single copy of hexanucleotide ( $0.8 \%$ ) (Fig. 6B). Comparative analysis revealed a total of $127,130,122,116$, 117 and 126 SSRs in L. balansae, L. hancei, C. henryi, C. sclerophylla, Q. pannosa and T. doichangensis, respectively. The majority of SSRs comprised of mono-nucleotides, followed by di-, tetra- and tri-nucleotides. These findings were consistent across all the compared genomes. The highest percentage of mono-nucleotide SSRs was found in T. doichangensis (73.8\%), followed by $C$. sclerophylla (70.6\%), while the least was recorded for L. balansae (63.7\%). Similarly, the percentage of dinucleotide SSRs was most significant in L.balansae (15.7\%), and the least was observed in T. doichangensis (10.3\%). However, the number of hexa, hepta, octa, nona and deca-nucleotides ranged between 0-2 in the compared Quercoideae genomes. The majority of the mono-nucleotide SSRs had A/T rich sequences and rarely contained any $\mathrm{C} / \mathrm{G}$ regions. The highest number of A/T rich repeats was found in T. doichangensis (91 nos), followed by L. hancei (82 nos), and the least was recorded in L. balansae and Q. pannosa with 75 repeats. Similarly, the di-nucleotide repeats were rich in AT/AT compared to AG/CT and were highest in L. balansae (16) and lowest in T. doichangensis (10) (Fig. 6C). SSR density was relatively greater in C. sclerophyla and Q. pannosa (with about $1.4 \mathrm{~kb} / \mathrm{SSR}$ ) than the cp genomes of the other compared species. The least SSR density was recorded in L. hancei (with approximately $1.23 \mathrm{~kb} /$ SSR) (Fig. 6D). 


\section{Nucleotide diversity}

The comparative analysis of the coding and non-coding regions was carried out to determine the variations in the hotspot regions of Lithocarpus, Quercus, Castanea and Castanopsis chloroplast genomes. We found high divergence in non-coding regions than the protein-coding regions. The nucleotide diversity $(P I)$ for proteincoding regions ranged from 0.00059 (ycf2) to 0.09132 (rp/33) for Lithocarpus (Fig. 7A). Whereas in Quercus, the nucleotide diversity of protein coding regions ranged from 0.0002 (rp/23) to 0.03146 (rp/36), in Castanea it ranged from 0.000256 to 0.00533 , and in Castanopsis it ranged from 0.000175 to 0.13913 (Fig. 7A). Furthermore, Castanopsis had the highest average nucleotide diversity (0.006989) for protein-coding genes, followed by Lithocarpus (0.0066), Quercus (0.0034) and Castanea (0.001617). We observed five highly diverged coding regions in each members of Quercoideae such as rp/33, petB, rp/32, ndhA and rp/22 in Lithocarpus, rp136, ndhJ, petG, rps15 and ndhF in Quercus, atpF, psal, ndhF, psbl and matK in Castanea and rp/36, petB, atpF, ycf3 and rp/22 in Castanopsis. However, across the studied four members of Quercoideae, the coding loci such as $r p / 36, r p / 33, n d h J$, atpF and $n d h A$ were highly diverge. The nucleotide diversity $(P I)$ on the other hand for noncoding regions ranged between 0.000278 (ycf2_trnL-CAA) and 0.04390 (trnH-GUG_psbA) for Lithocarpus (Figure S2a), 0.000536 (ndhB_rps7) and 0.013736 (petA_psbJ) for Quercus (Figure S2b), 0.000605 (ycf4_cemA) and 0.028562 (trnH_GUG_psbA) for Castanea (Figure S2c), and 0.000691 (ndhG_ndh) and 0.027903 (rbcL_accD) for Castanopsis (Figure S2d). Overall, Lithocarpus had greater average nucleotide diversity (0.009315) of non-coding regions than Castanopsis (0.006118), Quercus (0.005901) and Castanea (0.005159). The highly diverged non-coding regions such as $\operatorname{trnH}-G U G \_p s b A, r b c l \_a c c D, c s s A \_n d h D$, trnF-GAA_psbA and psbK_psb/ were found in Lithocarpus, followed by Quercus (petA_psbJ, atpF_atpH,psaC_ndhE, ycf4_cemA and atpl_rps2), Castanea (ndhG_ndhl, rbcL_accD, psbC_trnS_UGA, ccsA_ndhD and psaJ_rp/33) and Castanopsis (rbcL_accD, ccsA_ndhD, psbK_psbl, psaJ_rp/33 and psal_ycf4).

\section{Substitution rate}

The non-synonymous substitution (Ka) to synonymous substitution (Ks) ratios were calculated to understand the evolutionary pressure acting on the protein-coding sequences. A total of 79 shared protein-coding genes across all three Lithocarpus chloroplast genomes were utilised for calculating Ka/Ks ratios (Fig. 8). In the current analysis, the $\mathrm{Ka} / \mathrm{Ks}$ ratio for 34 genes were zero. However, 37 genes revealed $\mathrm{Ka} / \mathrm{Ks}$ ratio between the range of 0 and 1.0 , which shows that these genes were under the purifying selection. The Ka/Ks ratios of eight genes ( $a c c D, c e m A$, matK, ndhG, petB, rps2, rps3and rps12) were greater than 1 , indicating the positive selection acting on protein-coding genes. The average $\mathrm{Ka} / \mathrm{Ks}$ ratio for 45 genes was 0.52 .

\section{RNA editing}

The RNA editing sites in the $L$. dealbatus chloroplast genome were predicted using the program PREP suite. Overall, the programme predicted 55 editing sites in the 23 protein-coding genes (Fig. 9). All the substitution sites were from nucleotide base $\mathrm{C}$ to $\mathrm{T}$. The analysis showed that most conversions were observed from the amino acid serine to leucine, followed by proline to leucine. The highest substitutions viz., 42 and 13 occurred at the second and first codon positions, whereas no editing was detected at a third base location of the codon. Of the 55 editing sites, we observed the highest editing sites in $n d h B$ (10 sites), followed by $n d h D(5$ sites) and $r p o B$ (5 sites) genes. Fifty two RNA editing sites in the L. dealbatus chloroplast genome were responsible for 
hydrophobic amino acid changes, like isoleucine, leucine, proline, phenylalanine, methionine, valine, tyrosine, cysteine and tryptophan.

Comparative analysis among the Quercoideae genomes revealed the presence of RNA editing sites in $L$. balansae (53 sites in 21 genes), L. hancei (54 sites in 20 genes), C. henryi (54 sites in 20 genes), C. sclerophylla (53 sites in 20 genes), Q. pannosa (55 sites in 21 genes) and T. doichangensis (55 sites in 21 genes) (Fig. 9). Meanwhile, some of the compared genomes showed gene-specific RNA editing sites such as $p s a /$ gene in $L$. dealbatus, ycf3 gene in Q. pannosa, rpl20 gene in L. balansae and psbB gene in T. doichangensis. However, the L. dealbatus genome showed a greater number of RNA editing genes than the other compared genomes, even though most editing sites were nearly similar (Table S1).

\section{Phylogenetic analysis of Quercoideae species}

In this study, a phylogenetic tree was constructed based on 95,904 bp nucleotide alignment by employing the $\mathrm{GTR}+\mathrm{G}+\mathrm{I}$ as a best-fitting model. The topology of phylogenetic tree was computed by ML method. The chloroplast genomes of 63 Quercoideae members were included by keeping two Fagus species as an out-group (Fig. 10). The phylogenetic tree showed that three Lithocarpus species made separate group sharing a common node with Clade-I of Quercus species. Among the three Lithocarpus species, L. dealbatus was closer to $L$. hancei than L. balansae. We observed that Quercus genus was the most diverse among the Quercoideae forming four different clades across phylogenetic tree. On the other hand, Castanopsis and Castanea formed two separate monophyletic groups and shared a common node. T. doichangensis was present at the basal position in the Quercoideae subfamily.

Molecular clock analysis suggests that the estimated lineage (stem) divergence time for Quercoideae members such as Lithocarpus-Quercus-Castopsis-Castenea was around 37.28 Mya (Figure S3). However, Lithocarus started evolution around 22.80 Mya from one clade of Quercus while Castenea-Castinopsis evolved around 23.63 Mya from Lithocarpus-Quercus (1st clade). The estimated lineage divergence time for Castenea was 21.02 Mya. The other clades of Quercus (2nd, 3rd, and 4th ) were having the lineage divergence times more than 23.90 Mya (Figure S3).

\section{Discussion}

Lithocarpus, a major Quercoideae genus in the Fagaceae family, contributes significantly to ecosystem structure and function of many sub-tropical forests, being the most dominant species [37]. It also provides renewable firewood/charcoal resources for the local communities [1]. Although it is an important species from ecological and economics perspective, a limited number of studies have been conducted on the species [6, 7, 911], particularly no genomics information on L. dealbatus is available. However, availability of chloroplast genomic resources is crucial to unravel the genetic architecture. In this context, we assembled the $L$. dealbatus chloroplast genome and carried out a comparative analysis with six other members of Quercoideae to comprehend the structural architecture of the chloroplast genome.

The size of the $L$. dealbatus chloroplast genome was $161,476 \mathrm{bp}$, which fell in the expected range (107-218 kb) of most angiosperm chloroplast genomes [21]. The typical quadripartite structure of the $L$. dealbatus chloroplast genome was consistent with the characteristics of the angiosperm chloroplast genomes in general 
[18]. The L. dealbatus chloroplast genome displayed a low GC content (36.7\%); this finding is similar to other reported genomes from Fagaceae family $[17,18]$.

The IR regions, on the other hand, have a greater GC content (42.7\%) than both the LSC and SSC regions, owing to the comparatively high GC content of rRNA genes $[17,18]$. Although gene content is nearly conserved in the analysed Lithocarpus chloroplast genomes, some subtle variations did exist.

The presence or absence of protein-coding genes constituted a notable difference amongst the genomes studied. We observed the loss of the $p s b Z$ gene in L. balansae and L. hancei genomes. Similar loss of $p s b Z$ gene was also identified in C. sclerophylla, T. doichangensis and other land plants [38]. In contrast, no loss of protein coding gene was noticed in $L$. dealbatus chloroplast genome. Similar observation was made in case of Striga hermonthica genome earlier [39]. Various studies mentioned the absence of the infA gene in the angiosperm chloroplast genomes [40]. In the present investigation too, the inf $A$ gene was absent in $C$. henryi and T. doichangensis. However, on several occasions, the missing chloroplast genes have been reported to be integrated into the nuclear genome $[21,25]$.

The chloroplast genome is known to be conserved in land plants although some structural variations are reported in genome like inversions that occur due to occasional rearrangement, which bring forth crucial data [41]. Our analysis reported no significant inversion in compared genomes except the small 275 bp size of inversion in the $T$. doichangens is genome. However, such small inversions are ubiquitous in angiosperm chloroplast genomes [35]. The mVISTA investigation showed that the non-coding regions were more variable than protein-coding regions, a regular trend observed in other chloroplast genomes $[16,43,44]$. The IR region showed a higher level of conservation than the LSC and SSC region, a similar finding noticed in other angiosperms [16]. The level of divergence in Lithocarpus genomes was calculated using nucleotide diversity $(P I)$ analysis. Consistent with the divergence pattern observed in most angiosperms, greater divergence was detected in Lithocarpus non-coding regions [29]. The majority of the hotspot divergence regions have been previously utilised to develop potential molecular markers [29]. Our analysis indicates that these highly divergent regions could be very informative in discriminating the Lithocarpus species.

The IR regions are considered as the most conserved region in chloroplast genomes [45]. In spite of this, several studies explained the role of contraction and expansion of IR regions in chloroplast genome size variations and rearrangement in plants $[41,45,46]$. Our comparative analysis revealed certain similarities and differences at the IR junctions in the compared genomes. Overall, IR regions were mostly conserved across the Lithocarpus genomes which was more or less consistent with previous reports pertaining to Castanopsis and Quercus genomes [16, 47]. However, the absence of the $y c f 1$ gene was noticed at IRA/SSC and IRB/LSC junctions in $Q$. pannosa and $T$. doichangens is species, respectively. Several workers have documented the loss of $y c f 1 \mathrm{gene}$ at the IR junctions in many land plants $[45,48]$. Among the compared genomes, we observed extensive rearrangements at the IR junctions in $T$. doichangensis. These variations are known to contribute significantly towards the evolution of chloroplast genome structure. Long and complex repeats play a pivotal role in genome rearrangement and divergence [49]. Due to high sequence variations, tandem repeats are ideal for developing physical and genetic maps $[50,51]$. Our results of repeat analysis revealed variations in total number of tandem repeats among the compared genomes, which is consistent with the earlier observations in Plantaginaceae and Schisandraceae chloroplast genomes $[45,52]$. Moreover, minor variation was noticed in the distribution of tandem repeats regarding type and length, similar to the distribution patterned described in other plants $[45,52]$. 
SSRs are widely distributed in the chloroplast genome and are found associated with sequence rearrangement and polymorphism $[45,53]$. In the current study, SSR density moderately varied in the compared genomes. The highest density of SSR was observed in $C$. henryi (1SSR/1.31 kb) followed by Q. pannosa (1SSR/1.37 kb) and C. sclerophyla (1SSR/1.38 kb). The density of SSRs detected in the present investigation was greater in comparison to rice and the members of Solanaceae family $[54,55]$. Of the total SSR repeats, mononucleotides were the most abundant repeats followed by dinucleotide and tri-nucleotide repeats as stated in the earlier studies $[56,57]$. Interestingly, the population of A/T repeats was far more significant than $G / C$ repeats in mononucleotide repeats. A similar distribution of SSRs was noticed in the Fagaceae species and other angiosperms $[56,57]$. These findings suggest that the repeats mined in the current study can be utilised to develop molecular markers for studying population genetics, phylogeny, and differentiation of L. dealbatus and other members of Fagaceae.

RNA editing is an essential post-transcriptional mechanism observed in land plants. Identifying RNA editing sites in chloroplast genes help us to comprehend the underlying regulatory process(es) and its biological significance $[46,58]$. We detected 53-55 RNA editing sites in 20-23 protein-coding genes across the compared genomes. The $L$. dealbatus chloroplast genome exhibited the highest RNA editing genes (in 23 genes) compared to closely related $L$. balansae (in 21 genes) and $L$. hancei (in 20 genes) genome. In a broad sense, the number of RNA editing genes and sites are variable in chloroplast genomes [27]. We found three gene-specific RNA editing sites in the present investigation. However, the loss or gain of editing sites and their frequencies is an independent even that arises through mutations in RNA editing factors or stress interference [58-60]. Consistent with the previous reports, the highest number of editing sites were detected in the $n d h B(10$ sites) and $n d h D$ (8 sites) genes $[27,58]$. We noticed frequent conversions at the second base position of the codon that may change the corresponding amino acid leading to alterations in protein primary, secondary or tertiary structures. Consequently, such modifications can play a crucial role in protein functioning [46]. Generally, most RNA editing conversions result in hydrophobic amino acid change, thus influencing the protein structure $[27,46]$. Therefore, comprehensive investigation of RNA editing sites is an inevitable exercise that requires further attention in future.

The occurrence of point mutations through synonymous and non-synonymous nucleotide substitutions is crucial for gene evolution [61]. The calculation of $\mathrm{Ka} / \mathrm{Ks}$ ratios has been extensively used to detect evolutionary pressure acting on protein-coding genes $[53,62]$. Most protein-coding genes from Lithocarpus showed Ka/Ks ratios less than 1 , which is consistent with the previous reports $[50,63]$. This suggests that the majority of genes are under purifying selection. However, 34 genes showed $\mathrm{Ka} / \mathrm{Ks}$ ratio of 0 ; such ratios were observed when the Ks values were either very low or no substitution present between the aligned sequence [28]. We observed positive selection in eight Lithocarpus chloroplast genes ( $a c c D, c e m A$, matK, ndhG, petB, rps2, rps3and rps12) with $\mathrm{Ka} / \mathrm{Ks}$ values greater than 1 . These genes have also been reported for positive selection in other species [64]. Overall, the average $\mathrm{Ka} / \mathrm{Ks}$ ratio (0.52) of Lithocarpus clade reported in the present investigation was greater than that observed in the Cordylis species (0.26) [64], suggesting a possible evolutionary change in certain genes.

DNA barcoding is a fast and accurate method for identifying species by employing short piece of genomic DNA. However, as such no single universal barcode is available hitherto, which can discriminate the taxa up to species level $[15,17]$. Very recently, researchers have employed novel strategies to overcome these issues 
through two approaches i.e. DNA hotspot regions and super-barcoding [31, 32, 48, 57, 65]. Here, we have used the first approach to suggest the DNA divergent regions for resolving taxonomic conflicts and proposed a DNA barcode in four members of Quercoideae. We suggest five highly diverged coding (such as rp/33, petB, rp/32, ndhA and rpl22 in Lithocarpus, rp136, ndhJ, petG, rps15, ndhF in Quercus ;atpF, psal, ndhF, psbl, matK in Castanea, rp/36; and petB, atpF, ycf3,rp/22 in Castanopsis) and non-coding regions (trnH-GUG_psbA, rbcl_accD, cssA_ndhD, trnF-GAA_psbA, psbK_psb/in Lithocarpus; petA_psbJ, atpF_atpH, psaC_ndhE, ycf4_cemA and atpl_rps2 in Quercus; ndhG_ndhl, rbcL_accD, psbC_trnS_UGA, ccsA_ndhD, psaJ_rp/33 in Castanea, and rbcL_accD, ccsA_ndhD, psbK_psbl, psaJ_rp/33, psal_ycf4 in Castanopsis) from each genus by comparing chloroplast genome sequences. However, comparative study among the four genera revealed five highly diverged coding regions ( $r p / 36, r p / 33, n d h J$, atpF, and $n d h A$ ), which could be used to resolve inter-generic discrepancies in the aforementioned genus. Similar experiments were carried out in other studies, with the exception of a different number of highly variable regions [31, 48,57]. The majority of the discovered barcodes in the current study were not reported as universal markers in previous studies, implying that all loci are not phylogenetically effective in resolving taxonomic discrepancies $[15,17,60]$. Therefore, the designing of intraand inter-generic barcodes would be helpful to achieve greater phylogenetic resolution.

Recently, researchers proposed the utility of the whole chloroplast genome as a "super-barcode", which has provided a new perspective in plant identification and species delimitation [57-58]. Previous studies in Quercus revealed low phylogenetic resolution using the universal barcodes such as $r b c L$, matK, and $\operatorname{trnH}-p s b A[15,17]$. Thus, increasing number of investigations are employing the whole chloroplast genome to overcome the low resolving power of single-locus markers for evaluating phylogenetic relationships [36, 43]. In the present study, resolving the phylogeny between Lithocarpus and other Quercoideae species could give insights into the evolutionary relationship in Fagaceae family. Lithocarpus genus formed a monophyletic group in which $L$. hancei and L. balansae were closely associated. The loss of $p s b Z$ gene in L. hancei and L. balansae genome is also confirming such phylogenetic relationship.

L. dealbaatus was more closely related to $L$. hanceithan L. balansae, which is well-supported by sequence homology analysis. The Lithocarpus clade shared a common node with the Quercus species of clade-I, which is consistent with the high coverage and sequence similarity between some Quercus and Lithocarpus species. At the same time, molecular dating analysis revealed the divergence time for Lithocarpus from Quercus clade at 22.80 Mya in the early Miocene Epoch period. A near-similar divergence time was estimated for the separation of the Quercus and Lithocarpus genus based on the five genes by Larson-Johnson (2016). Furthermore, phylogeny analysis suggests that Castanea and Castanopsis, two closely diverged genus, spitted 21.02 Mya, which is in conformity with the previous morphological and molecular studies [30,68]. On the other hand, $T$. doichangensis present at the basal position and showed as an early diverged genus in the Quercoideae subfamily. This is well supported by the previous fossil records [69]. Besides this, Quercus appeared as the most diverse species forming four distinct clades across phylogenetic tree [30,70]. This could be because of endemism and allopatric speciation among Quercus species that may have amplified genetic and morphological variations in the course of species evolution [18]. However, the phylogenetic relationship of oak is complex owing to a considerable level of hybridisation, introgression, incomplete lineage sorting and convergent evolution [71]. In general, ourtree topology (Fagus, Trigonobalanus, Quercus, Castanopsis, Castanea, Lithocarpus, and Quercus) is more or less similar to the earlier phylogenetic outcome [33]. 


\section{Conclusions}

In conclusion, the present investigation successfully assembled and annotated the complete chloroplast genomes of L. dealbatus with the MGI technology. The gene contents and synteny of the Lithocarpus chloroplast genomes were nearly conserved. A significant sequence homology was found among $L$. dealbatus, L. balansae and $L$. hancei. Analysis of repeat elements revealed a minor level of variations in the total number of repeat elements across analyzed genomes. The ML tree clearly showed the formation of monophyletic group for Lithocarpus species, and the whole clade of Lithocarpus was closely related to Quercus species. The comparative analysis of chloroplast genomes of $L$. dealbatus with that of other members of Quercoideae strengthened our understanding of evolutionary lineage. In addition, the mutational hotspot regions mined in the current investigations could be helpful to discriminate the closely related species in Quercoideae. We recommend that the highly mutational diverge regions should be used as a potential barcode for better resolution of species in various genera of Quercoideae. The newly proposed barcodes in silico identified in this study is required to be validated their extent of resolution power for species delimitation and phylogenetic reconstruction. This study has provided crucial insights into the characteristic features of chloroplast genome of $L$. dealbatus, the divergence hotspot regions and repeat elements, which can be utilized as molecular markers for further studies in population genetics.

\section{Methods}

\section{DNA isolation and DNB sequencing on MGI platform}

Fresh leaf samples of $L$. dealbatus were collected from Shillong, Meghalaya and stored immediately in liquid nitrogen. DNA extraction was performed from the stored leaf samples using DNeasy Plant Pro and Plant Kits (Qiagen).The quality of the extracted genomic DNA was determined in $0.8 \%$ agarose gel and further quantified through NanoDrop ${ }^{\text {TM }}$ One/OneC Micro volume UV-Vis Spectrophotometer (Thermofischer). The genomic library was constructed following the MGI's instructions (ILS Pvt. Ltd). DNBSEQ ${ }^{T M}-$ G400 Genetic Sequencer (MGI) platform at Imperial Life Sciences Pvt. Ltd was used to generate PE150long reads.

\section{Chloroplast genome assembly}

The quality of MGI reads was checked through the FastQC program (https://www.bioinformatics.babraham.ac.uk/projects/fastqc/). The clean reads were further used to denovo assemble the whole chloroplast genome through Novoplasty assembler by keeping the default parameter except Kmer length 39 and $r b c L$ gene as a seed sequence from L. balansae genome (KP299291.1) [34]. The assembled chloroplast genome was confirmed by performing BLASTN against the non-redundant nucleotide database at NCBI (https://blast.ncbi.nlm.nih.gov/Blast.cgi?PAGE_TYPE=BlastSearch).

\section{Annotation and map drawing of chloroplast genome}

The chloroplast genome was further annotated using the Chlorobox Geseq program, keeping L. balansae and in build the Geseq MPI-MP genome set as a reference genome (https://chlorobox.mpimpgolm.mpg.de/geseq.html). Annotations of tRNA genes were conducted through the tRNAscan-SE tool. Manual adjustment of start and stop codon and exon-intron junctions were made in the NCBI ORF finder. Finally, 

[35].

\section{Comparative analysis of $\mathrm{L}$. dealbatus with Fagaceae chloroplast genome for structural rearrangement, similarity, expansion and contraction of IR and tandem repeat}

Comparative analysis of the $L$. dealbatus chloroplast genome was performed using the previously published genomes such as L. balansae (KP299291.1), L. hancei (MW375417.1), C. henryi (MH998384.1), C. sclerophylla (NC_044680.1), Q. pannosa (NC_050963.1) and T. doichangensis (KF990556.1). Structural rearrangement among the chloroplast genomes was recognised through MAUVE alignment (http://darlinglab.org/mauve/mauve.html). The mVISTA program was employed to determine the similarity between the compared chloroplast genomes using the Shuffle-LAGAN model by keeping L. dealbatus as a reference (http://genome.lbl.gov/vista/mvista/submit.shtml). The expansion and contraction of IR junctions in chloroplast genomes were analysed and displayed through the IRscope tool (https://irscope.shinyapps.io/irapp/). Tandem repeats were identified through the REPuter program using the minimum repeat size 30 and hamming distance 3 (https://bibiserv.cebitec.uni-bielefeld.de/reputer/). MISA tool was employed to recognise SSRs with the minimum repeats 10 for mono-nucleotide, 5 for di-nucleotide, 4 for trinucleotide, 3 for tetra-, penta-, hexa-, septa-, octa-, nona- and deca- nucleotide, respectively (http://pgrc.ipkgatersleben.de/misa/misa.html).We employed the Predictive RNA Editor for Plants (PREP) program to recognise the RNA editing in 35 reference genes (http://prep.unl.edu/).

\section{DNA diversity and $\mathrm{Ka} / \mathrm{Ks}$ analysis in Lithocarpus}

Divergence across the coding and non-coding regions in the Lithocarpus, Quercus, Castanea and Castanopsis genus was determined using DnaSP v5.0 (Universitat de Barcelona, Barcelona, Spain)

(http://www.ub.edu/dnasp/). MEGA X tool was used to determine the Ka/Ks ratio of protein-coding regions (https://www.megasoftware.net/).

\section{Phylogenetic analysis and estimation of the divergence time}

Phylogenetic study was performed using the chloroplast genomes of Quercoideae genomes available in the public database. We selected two chloroplast genomes from the genus Fagus namely F. crenata and $F$. japonica, as outgroups. Direct alignment of chloroplast genomes is challenging to exercise due to structural rearrangements and gene content. Hence, we employed the HomBlocks tool to determine locally collinear blocks (LCBs) present in chloroplast genomes for alignment [36]. Unaligned sequences were trimmed using the Gblocks program embedded in the HomBlocks pipeline. The best substitution model was calculated by Model test in the MEGA tool suggested by the Akaike information criterion (AIC). Finally, the GTR $+G+I$ model was chosen to construct the phylogenetic tree using the maximum likelihood (ML) method in the MEGA X tool (https://www.megasoftware.net/). The branch support values for each were calculated based on 500 bootstraps. The phylogenetic tree was coloured and represented using the iTOL web server (https://itol.embl.de/). 
A timetree was inferred using the ReltimeML-option in MEGA X. The same species used in our previous analysis such as F. crenata and F. japonica were constrained to be the outgroup in this divergence tree analysis. The reference node age was obtained by the divergence time of Quercus ciliaris- T. diochangensis (11.1-57.9 million years ago) and $Q$. ciliaris-C.henryi (6.0-49.0 million years ago) (http://www.timetree.org/).

\section{Declarations}

\section{Ethics approval and consent to participate:}

Manuscript number allotted by CSIR ethical committee: CSIR-NBRI_MS/2022/01/03

\section{Consent for publication:}

Not applicable

\section{Availability of data and materials:}

The assembled genome can be accessed in NCBI database with accession number MZ322408.

\section{Competing interests:}

The authors declare that they have no competing interests.

\section{Funding:}

Partially supported from NMHS project (Grant No. NMHS 2015-16/LG06/06).

\section{Author contributions:}

Conceptualization: SKB and SNJ; Sample collection and DNA isolation: BJ, PPS, GT and DA; genome assembly and annotation: RGS; experiment designing and data analysis: SKB, SNJ, RGS and RPB; manuscript draft preparation: RGS, RPB, and SNJ; Supervised the study and critical revision of the manuscript: SK

\section{Acknowledgments:}

We acknowledge the Director, CSIR-National Botanical Research Institute, Lucknow for the lab infrastructure. We acknowledge the sequencing support from Dr. Ravi Chilukoti, MGI, India, Dr.Ratnesh Tripathi and Mr. Ashfaq, ILS, Guargaon.

\section{References}

1. Singh B, Singh B. Fagaceae contribution to floral wealth of Himalaya: Checklist on diversity and distribution in North-eastern states of India. Curr Life Sci. 2016;2:72-78-78.

2. Bhatt D, Sekar KC, Kumar K. Tree diversity of Indian Himalayan region. 2020.

3. Tang CQ, Chiou CR, Lin CT, Lin JR, Hsieh CF, Tang JW, et al. Plant diversity patterns in subtropical evergreen broad-leaved forests of Yunnan and Taiwan. Ecol Res. 2013;28:81-92. 
4. Lehmann L, Greijmans M. Forests and trees of the central highlands of Xieng Khouang Lao PDR. DANIDA, Vientiane, 246p. 2003. http://m.mekonginfo.org/assets/midocs/0001714-environment-forests-and-trees-ofthe-central-highlands-of-xieng-khouang-lao-p-d-r-a-field-guide.pdf.

5. Singh PP, Chakraborty T, Dermann A, Dermann F, Adhikari D, Gurung PB, et al. Assessing restoration potential of fragmented and degraded fagaceae forests in Meghalaya, North-East India. Forests. 2020;11.

6. Rao P, Barik SK, Pandey HN, Tripathi RS. Community composition and tree population structure in a subtropical broad-leaved forest along a disturbance gradient. Vegetatio. 1990;88:151-62. doi:10.1007/BF00044832.

7. Barik SK, Pandey HN, Tripathi RS, Rao P. Microenvironmental variability and species diversity in treefall gaps in a sub-tropical broadleaved forest. Vegetatio. 1992;103:31-40. http://www.jstor.org/stable/20046218.

8. Vander Wall SB. The evolutionary ecology of nut dispersal. Bot Rev. 2001;67:74-117.

9. Barik SK, Tripathi RS, Pandey HN, Rao P. Tree. J Appl Ecol. 1996;33:1551-60. doi:10.2307/2404793.

10. Barik SK, Rao P, Tripathi RS, Pandey HN. Dynamics of tree seedling populations in a humid subtropical forest of northeast India as related to disturbance. Can J For Res. 1996;26:584-9. doi:10.1139/x26-067.

11. Rao P, Barik SK, Pandey HN, Tripathi RS. Tree seed germination and seedling establishment in treefall gaps and understorey in a subtropical forest of northeast India. Aust J Ecol. 1997;22:136-45. doi:https://doi.org/10.1111/j.1442-9993.1997.tb00652.x.

12. Manos PS, Steele KP. Phylogenetic analyses of "higher" Hamamelididae based on plastid sequence data. Am J Bot. 1997;84:1407-19.

13. Cavender-Bares, J., D.D. Ackerly, D.A. Baum FAB, Baum DA, Bazzaz FA. Phylogenetic overdispersion in floridian oak communities. Am Nat. 2004;163:823-43.

14. Manos, P.S. AMS. The historical biogeography of Fagaceae: tracking the tertiary history of temperate and subtropical forests of the northern hemisphere. Int J Plant Sci. 2001;162:S77-93.

15. Moran E V., Willis J, Clark JS. Genetic evidence for hybridization in red oaks (Quercus sect. Lobatae, Fagaceae). Am J Bot. 2012;99:92-100.

16. Ye X, Hu D, Guo Y, Sun R. Complete chloroplast genome of Castanopsis sclerophylla (Lindl.) Schott: Genome structure and comparative and phylogenetic analysis. PLoS One. 2019;14:1-14.

17. Pang X, Liu H, Wu S, Yuan Y, Li H, Dong J, et al. Species identification of Oaks (Quercus L., Fagaceae) from gene to genome. Int J Mol Sci. 2019;20.

18. Yang J, Vázquez L, Chen X, Li H, Zhang H, Liu Z, et al. Development of chloroplast and nuclear DNA markers for Chinese oaks (Quercus subgenus Quercus) and assessment of their utility as DNA barcodes. Front Plant Sci. 2017;8 May:1-17.

19. Piredda R, Simeone MC, Attimonelli M, Bellarosa R, Schirone B. Prospects of barcoding the Italian wild dendroflora: oaks reveal severe limitations to tracking species identity. Mol Ecol Resour. 2011;11:72-83. doi:10.1111/j.1755-0998.2010.02900.x.

20. Zhou H, Gao X, Woeste K, Zhao P, Zhang S. Comparative analysis of the complete chloroplast genomes of four chestnut species (Castanea). Forests. 2021;12:861. doi:10.3390/f12070861.

21. Song Y, Wang S, Ding Y, Xu J, Li MF, Zhu S, et al. Chloroplast genomic resource of paris for species discrimination. Sci Rep. 2017;7:3427. doi:10.1038/s41598-017-02083-7. 
22. Cosner ME, Raubeson LA, Jansen RK. Chloroplast DNA rearrangements in Campanulaceae: Phylogenetic utility of highly rearranged genomes. BMC Evol Biol. 2004;4:1-17.

23. Daniell H, Lin CS, Yu M, Chang WJ. Chloroplast genomes: Diversity, evolution, and applications in genetic engineering. Genome Biol. 2016;17:1-29. doi:10.1186/s13059-016-1004-2.

24. Nock CJ, Waters DLE, Edwards MA, Bowen SG, Rice N, Cordeiro GM, et al. Chloroplast genome sequences from total DNA for plant identification. Plant Biotechnol J. 2011;9:328-33.

25. Rogalski M, Vieira LDN, Fraga HP, Guerra MP. Plastid genomics in horticultural species: Importance and applications for plant population genetics, evolution, and biotechnology. Front Plant Sci. 2015;6 JULY:117.

26. Wicke S, Schneeweiss GM, dePamphilis CW, Müller KF, Quandt D. The evolution of the plastid chromosome in land plants: Gene content, gene order, gene function. Plant Mol Biol. 2011;76:273-97.

27. de Santana Lopes A, Pacheco TG, Santos KG dos, Vieira L do N, Guerra MP, Nodari RO, et al. The Linum usitatissimum $\mathrm{L}$. plastome reveals atypical structural evolution, new editing sites, and the phylogenetic position of Linaceae within Malpighiales. Plant Cell Rep. 2018;37:307-28. doi:10.1007/s00299-017-2231$z$.

28. Mo Z, Lou W, Chen Y, Jia X, Zhai M, Guo Z, et al. The chloroplast genome of Carya illinoinensis: Genome structure, adaptive evolution, and phylogenetic analysis. Forests. 2020;11.

29. Menezes APA, Resende-Moreira LC, Buzatti RSO, Nazareno AG, Carlsen M, Lobo FP, et al. Chloroplast genomes of Byrsonima species (Malpighiaceae): Comparative analysis and screening of high divergence sequences. Sci Rep. 2018;8:1-12. doi:10.1038/s41598-018-20189-4.

30. Liu X, Chang E, Liu J, Huang Y, Wang Y, Yao N, et al. Complete chloroplast genome sequence and phylogenetic analysis of Quercus bawanglingensis Huang, Li et Xing, a vulnerable oak tree in China. Forests. 2019;10:587.

31. Khan A, Asaf S, Khan AL, Shehzad T, Al-Rawahi A, Al-Harrasi A. Comparative chloroplast genomics of endangered Euphorbia species: insights into hotspot divergence, repetitive sequence variation, and phylogeny. Plants. 2020;9:199. doi:10.3390/plants9020199.

32. Zhang W, Sun Y, Liu J, Xu C, Zou X, Chen X, et al. DNA barcoding of Oryza: conventional, specific, and super barcodes. Plant Mol Biol. 2021;105:215-28. doi:10.1007/s11103-020-01054-3.

33. Ma C, Yan H, Ge X, Zhejiang F. The complete chloroplast genome of Lithocarpus hancei ( Benth .) Rehd ( Fagaceae ) from Zhejiang , China. Mitochondrial DNA Part B. 2022;6:2022-3.

34. Dierckxsens N, Mardulyn P, Smits G. NOVOPlasty: De novo assembly of organelle genomes from whole genome data. Nucleic Acids Res. 2017;45.

35. Tillich M, Lehwark P, Pellizzer T, Ulbricht-Jones ES, Fischer A, Bock R, et al. GeSeq - Versatile and accurate annotation of organelle genomes. Nucleic Acids Res. 2017;45:W6-11.

36. Bi G, Mao Y, Xing Q, Cao M. HomBlocks: A multiple-alignment construction pipeline for organelle phylogenomics based on locally collinear block searching. Genomics. 2018;110:18-22.

37. Suchiang BR, Nonghuloo IM, Kharbhih S, Singh PP, Tiwary R, Adhikari D, et al. Tree diversity and community composition in sacred forests are superior than the other community forests in a human-dominated landscape of Meghalaya. Trop Ecol. 2020;61:84-105. doi:10.1007/s42965-020-00066-w. 
38. Mohanta TK, Mishra AK, Khan A, Hashem A, Abd-Allah EF, Al-Harrasi A. Gene loss and evolution of the plastome. Genes (Basel). 2020;11:1-23.

39. Frailey DC, Chaluvadi SR, Vaughn JN, Coatney CG, Bennetzen JL. Gene loss and genome rearrangement in the plastids of five Hemiparasites in the family Orobanchaceae. BMC Plant Biol. 2018;18:1-12.

40. Millen RS, Olmstead RG, Adams KL, Palmer JD, Lao NT, Heggie L, et al. Many Parallel Losses of infA from chloroplast DNA during angiosperm evolution with multiple independent. Plant Cell. 2001;13 March:64558.

41. Jin D-M, Jin J, Yi T. Plastome structural conservation and evolution in the clusioid clade of Malpighiales. Sci Rep. 2020;10:9091.

42. Catalano Santiago Andre's BOS and JC sar V, Departamento. Cladistics evolution of small inversions in chloroplast genome: a case study from a recurrent inversion in angiosperms. Cladistics. 2009;25:93-104.

43. Xu J, Shen X, Liao B, Xu J, Hou D. Comparing and phylogenetic analysis chloroplast genome of three Achyranthes species. Sci Rep. 2020;10:1-13. doi:10.1038/s41598-020-67679-y.

44. Zhu B, Qian F, Hou Y, Yang W, Cai M, Wu X. Complete chloroplast genome features and phylogenetic analysis of Eruca sativa (Brassicaceae). PLoS One. 2021;16 3 March:1-19. doi:10.1371/journal.pone.0248556.

45. Asaf S, Khan AL, Lubna, Khan A, Khan A, Khan G, et al. Expanded inverted repeat region with large scale inversion in the first complete plastid genome sequence of Plantago ovata. Sci Rep. 2020;10:3881. doi:10.1038/s41598-020-60803-y.

46. He P, Huang S, Xiao G, Zhang Y, Yu J. Abundant RNA editing sites of chloroplast protein-coding genes in Ginkgo biloba and an evolutionary pattern analysis. BMC Plant Biol. 2016;16:1-12. doi:10.1186/s12870016-0944-8.

47. Li X, Li Y, Zang M, Li M, Fang Y. Complete chloroplast genome sequence and phylogenetic analysis of Quercus acutissima. Int J Mol Sci. 2018;19:1-17.

48. Abdullah, Mehmood F, Shahzadi I, Waseem S, Mirza B, Ahmed I, et al. Chloroplast genome of Hibiscus rosasinensis (Malvaceae): Comparative analyses and identification of mutational hotspots. Genomics. 2020;112:581-91. doi:10.1016/j.ygeno.2019.04.010.

49. Song Y, Zhang Y, Xu J, Li W, Li MF. Characterization of the complete chloroplast genome sequence of Dalbergia species and its phylogenetic implications. Sci Rep. 2019;9:1-10. doi:10.1038/s41598-01956727-x.

50. Nie X, Lv S, Zhang Y, Du X, Wang L, Biradar SS, et al. Complete chloroplast genome sequence of a major invasive species, crofton weed (Ageratina adenophora). PLoS One. 2012;7.

51. Edwards A, Civitello A, Hammond HA, Caskey CT. DNA typing and genetic mapping with trimeric and tetrameric tandem repeats. Am J Hum Genet. 1991;49:746-56.

52. Li B, Zheng Y. Dynamic evolution and phylogenomic analysis of the chloroplast genome in Schisandraceae. Sci Rep. 2018;8:1-11. doi:10.1038/s41598-018-27453-7.

53. Shelke RG, Basak S, Rangan L. Development of EST-SSR markers for Pongamia pinnata by transcriptome database mining: cross-species amplification and genetic diversity. Physiol Mol Biol Plants. 2020;26:222541. doi:10.1007/s12298-020-00889-w. 
54. Rajendrakumar P, Biswal AK, Balachandran SM, Srinivasarao K, Sundaram RM. Simple sequence repeats in organellar genomes of rice: Frequency and distribution in genic and intergenic regions. Bioinformatics. 2007;23:1-4.

55. Tambarussi EV, Melotto-Passarin DM, Gonzalez SG, Brigati JB, Jesus FA, Barbosa AL, et al. In silico analysis of simple sequence repeats from chloroplast genomes of Solanaceae species. Crop Breed Appl Biotechnol. 2009;9:344-52. doi:10.12702/1984-7033.v09n04a09.

56. Silva SR, Pinheiro DG, Penha HA, Płachno BJ, Michael TP, Meer EJ, et al. Intraspecific variation within the utricularia amethystina species morphotypes based on chloroplast genomes. Int J Mol Sci. 2019;20:1-19.

57. Mehmood F, Shahzadi I, Waseem S, Mirza B, Ahmed I. Chloroplast genome of Hibiscus rosa-sinensis ( Malvaceae ): Comparative analyses and identification of mutational hotspots. Genomics. 2020;112:58191.

58. Freyer R, Kiefer-Meyer M-C, Kossel H. Occurrence of plastid RNA editing in all major lineages of land plants. Proc Natl Acad Sci. 1997;94:6285-90.

59. Rodrigues NF, Christoff AP, da Fonseca GC, Kulcheski FR, Margis R. Unveiling chloroplast RNA editing events using next generation small RNA sequencing data. Front Plant Sci. 2017;8 September.

60. Small ID, Schallenberg-Rüdinger M, Takenaka M, Mireau H, Ostersetzer-Biran O. Plant organellar RNA editing: what 30 years of research has revealed. Plant J. 2020;101:1040-56.

61. Kimura M, editor. Introduction. In: The neutral theory of molecular evolution. Cambridge: Cambridge University Press; 1983. p. xi-xvi. doi:10.1017/CB09780511623486.002.

62. Wang D, Zhang Y, Zhang Z, Zhu J, Yu J. KaKs_Calculator 2.0: A toolkit incorporating gamma-series methods and sliding window strategies. Genomics, Proteomics Bioinforma. 2010;8:77-80.

63. Yang Y, Hu Y, Ren T, Sun J, Zhao G. Remarkably conserved plastid genomes of Quercus group Cerris in China: comparative and phylogenetic analyses. Nord J Bot. 2018;36.

64. Xu X, Wang D. Comparative chloroplast genomics of Corydalis Species (Papaveraceae): evolutionary perspectives on their unusual large scale rearrangements. Front Plant Sci. 2021;11 January:1-16. doi:10.3389/fpls.2020.600354.

65. Liu L, Wang Z, Huang L, Wang T, Su Y. Chloroplast population genetics reveals low levels of genetic variation and conformation to the central-marginal hypothesis in Taxus wallichiana var. mairei, an endangered conifer endemic to China. Ecol Evol. 2019;9:11944-56.

66. Basak S, Chakrabartty I, Hedaoo V, Shelke RG, Rangan L. Assessment of genetic variation among wild Alpinia nigra (Zingiberaceae) population: an approach based on molecular phylogeny. Mol Biol Rep. 2019;46:177-89. doi:10.1007/s11033-018-4458-3.

67. Larson-Johnson K. Phylogenetic investigation of the complex evolutionary history of dispersal mode and diversification rates across living and fossil Fagales. New Phytol. 2016;209:418-35.

68. Manos PS, Cannon $\mathrm{CH}$, Oh S-H. Phylogenetic relationships and taxonomic status of the paleoendemic Fagaceae of Western North America: Recognition of a new genus, Notholithocarpus. Madroño. 2008;55:181-90.

69. Zhekun Z. Fossils of the Fagaceae and their implications in systematics and biogeography. Acta Phytotaxonomica Sinica. 1999;37:369-85. 
70. Yang J, Huang Y, Yang Z, Zhou C, Hu X. Identification and quantitative evaluation of major sweet ingredients in sweet tea (Lithocarpus polystachyus Rehd.) based upon location, harvesting time, leaf age. J Chem Soc Pakistan. 2018;40:158-64.

71. Aldrich PR, Cavender-bares J. Wild crop relatives: Genomic and Breeding Resources. 2011.

\section{Figures}

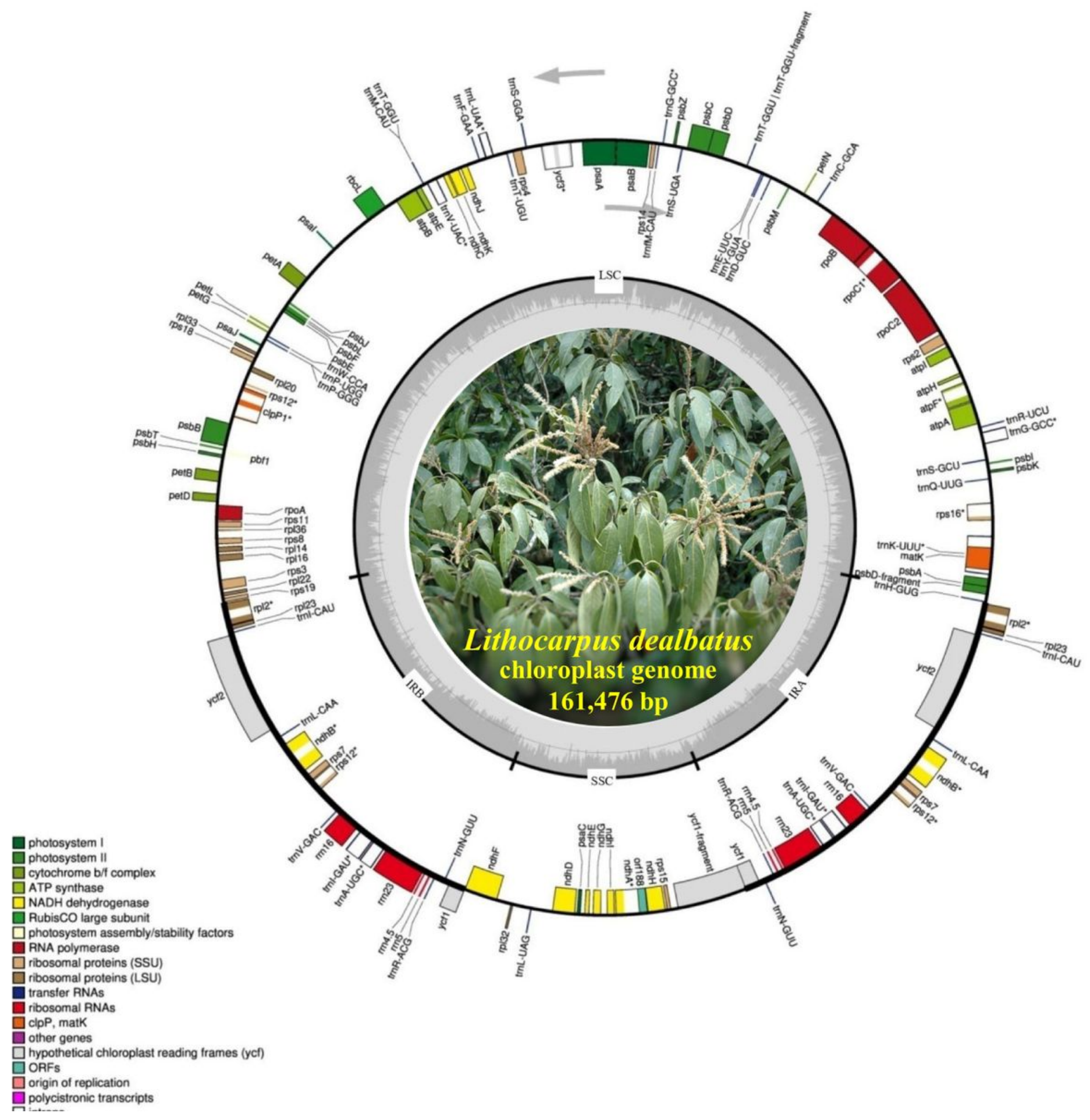

Figure 1 
Circular map of Lithocarpus dealbatus chloroplast genome representing the annotated genes in different colours according to their specific functions. The genes present on the inner circular map were transcribed clockwise, and those situated outside were transcribed anti-clockwise. The darker grey colour inside the circle shows the GC content, while the lighter grey colour indicating the AT content. The chloroplast genome borders were demarcated as LSC, SSC, IRA and IRB regions

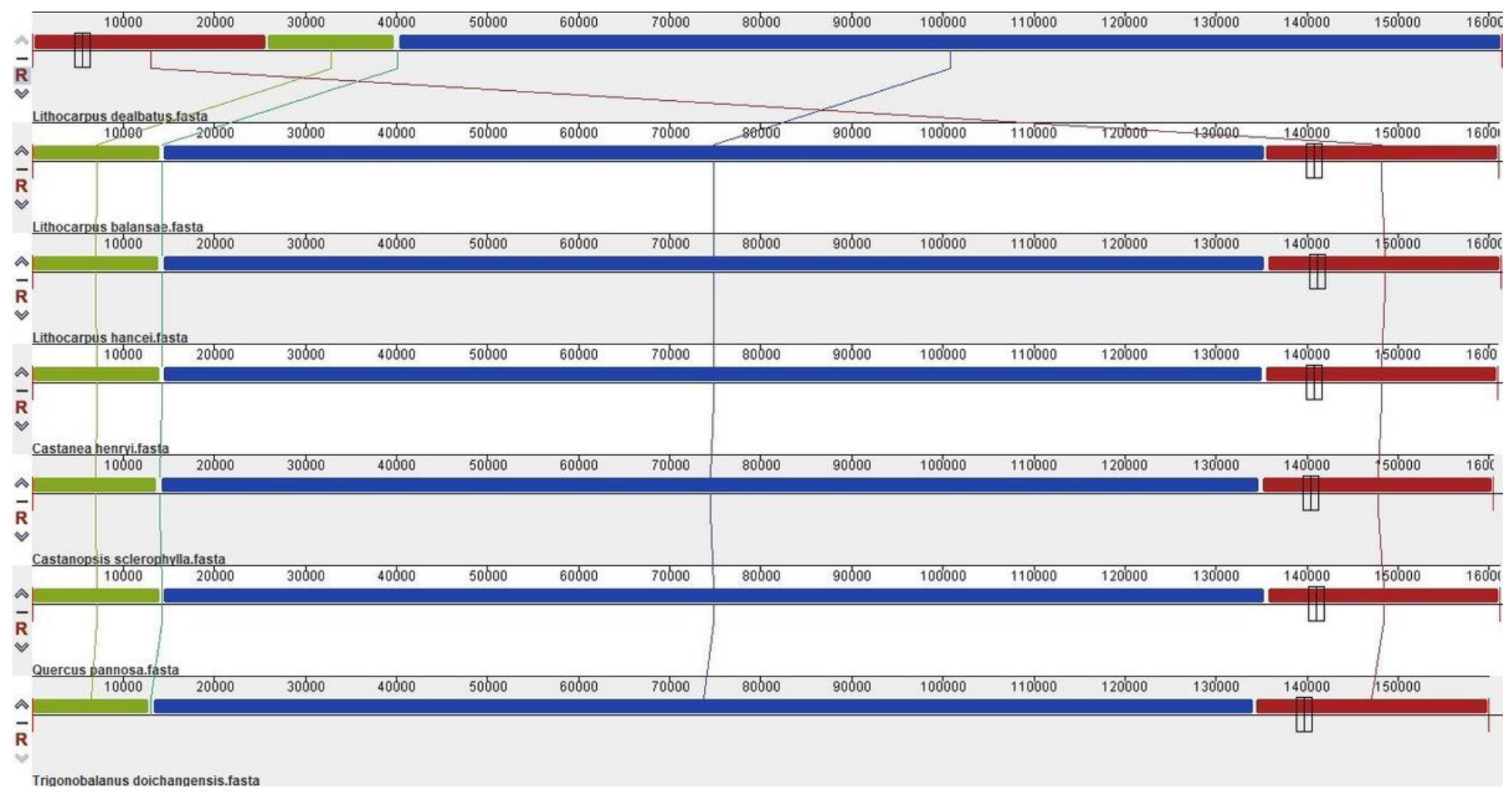

\section{Figure 2}

MAUVE alignment of $L$. dealbatus chloroplast genome against some of the representative species from Quercoideae. Within each of the alignments, the local colinear blocks indicate the identical conserved regions represented by the same colour and are joined by lines 
L. dealbatus

L. balansae

C. henryi

C. sclerophylla

Q. pannosa

T. doichangensis
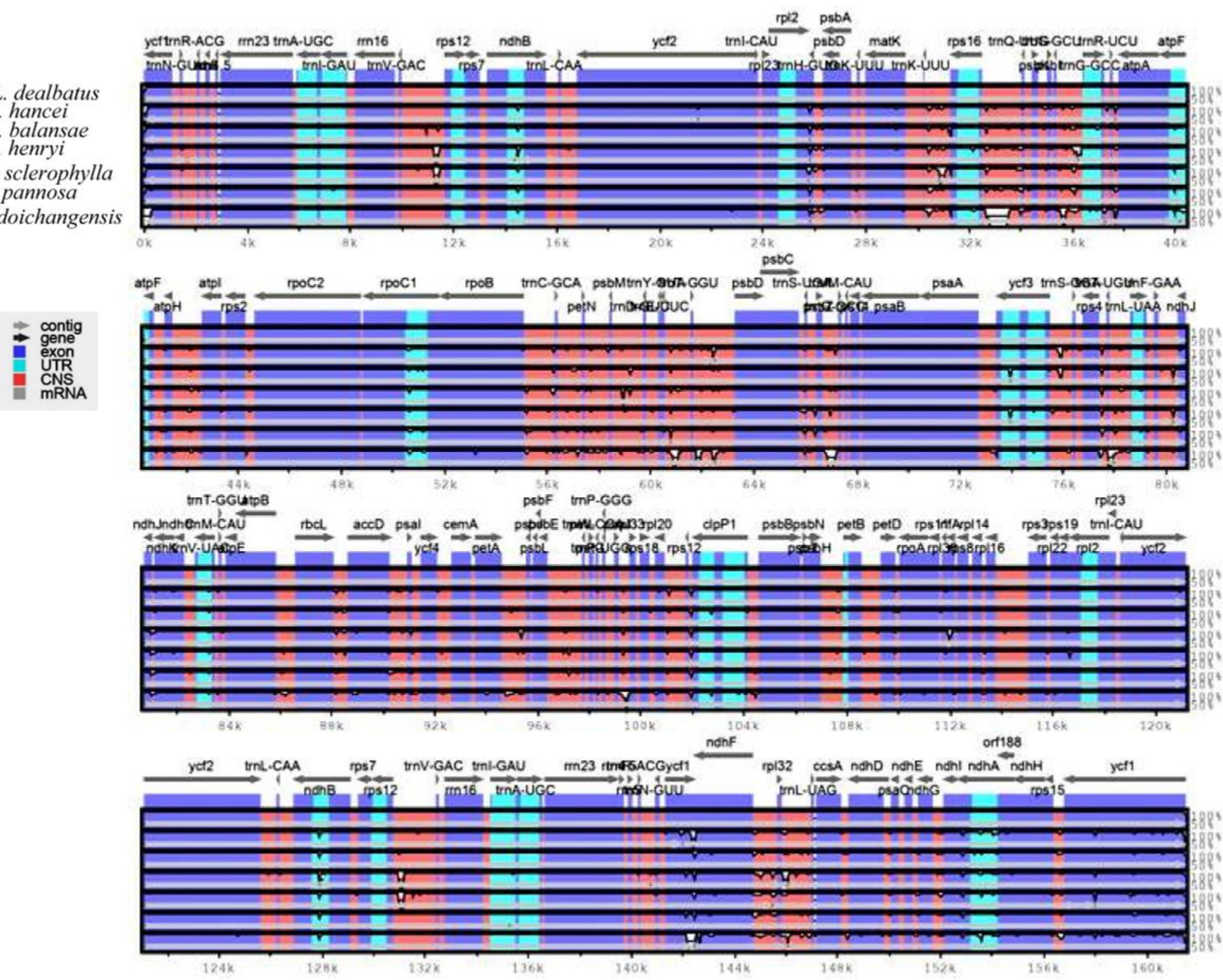

\section{Figure 3}

Sequence alignment of Quercoideae chloroplast genomes by MVISTA, with annotation L. dealbatus chloroplast genome as the reference 


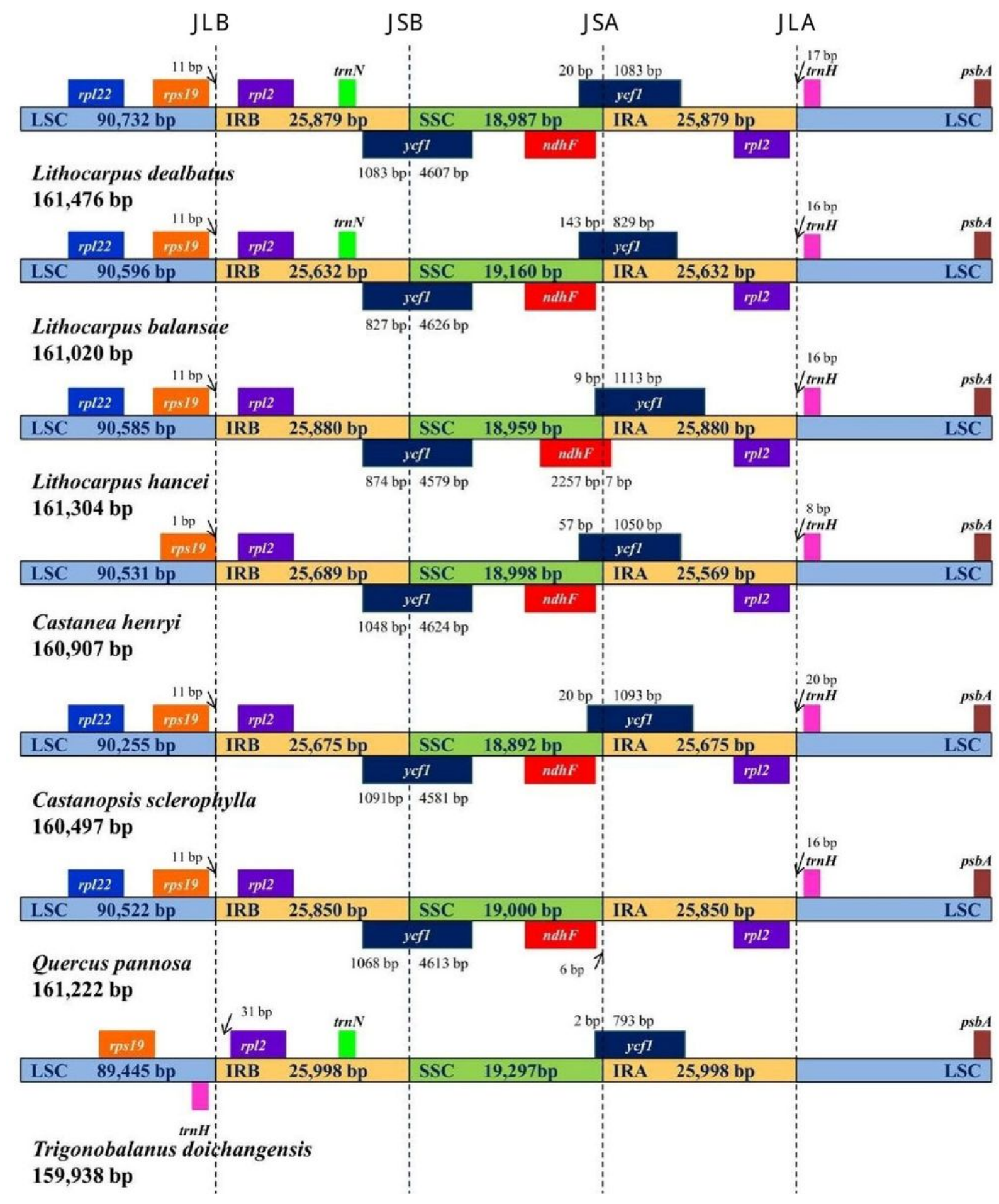

\section{Figure 4}

Details of junction positions between inverted repeat regions and small and large single-copy regions across the compared Quercoideae genomes. Each gene is depicted in different colours. The genes present on top are transcribed on the positive strand, whereas those present below are transcribed on the negative strand. The complete genome size of each species is mentioned on the left side 
A

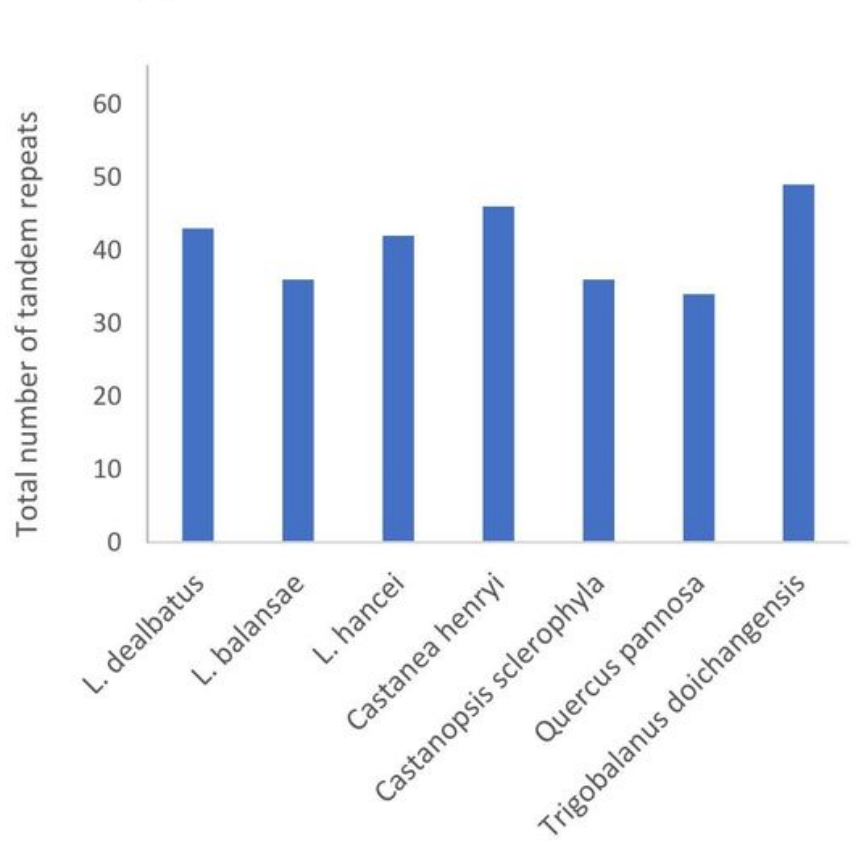

B

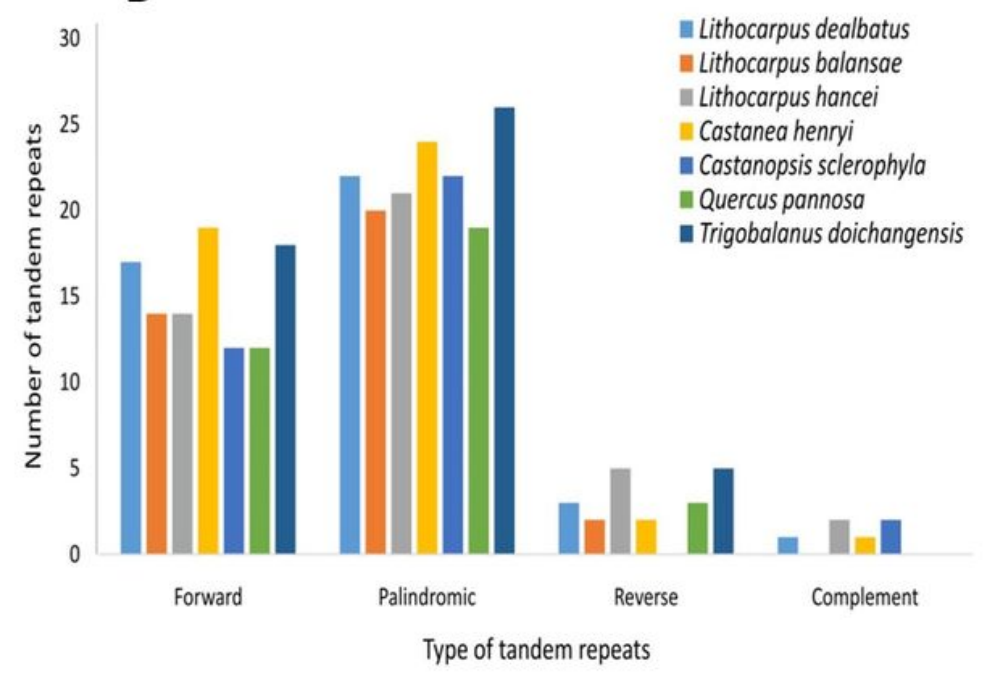

\section{C}

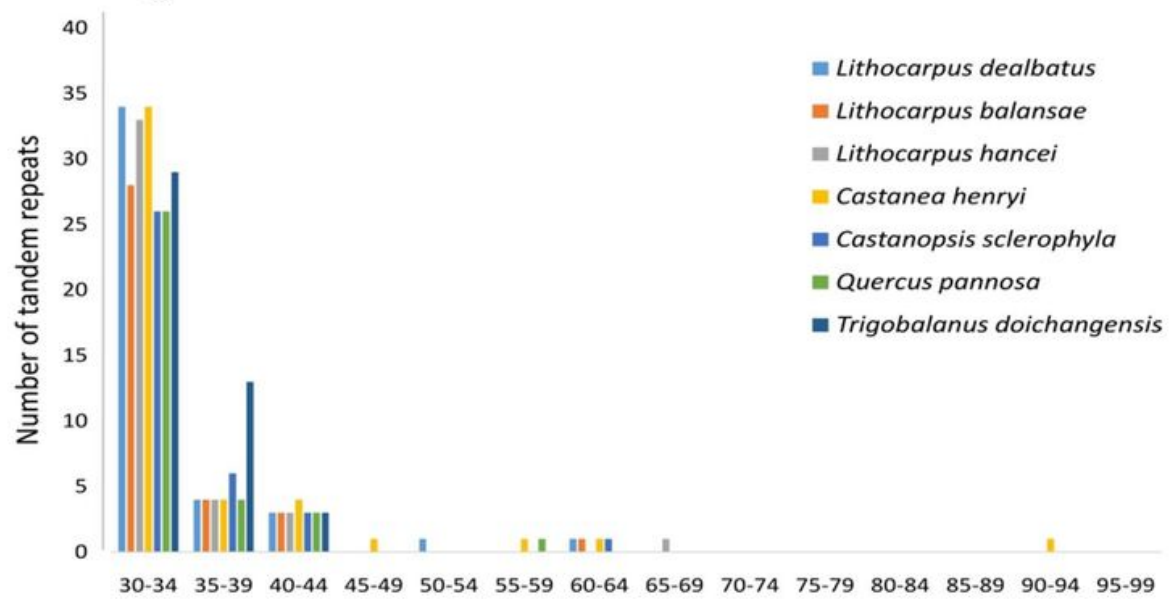

Size of tandem repeats (bp)

\section{Figure 5}

Comparative analysis of tandem repeats across compared genomes, A. Distribution of tandem repeats based upon their type in the chloroplast genome, B. Frequency of tandem repeats based on their size in the chloroplast genome 

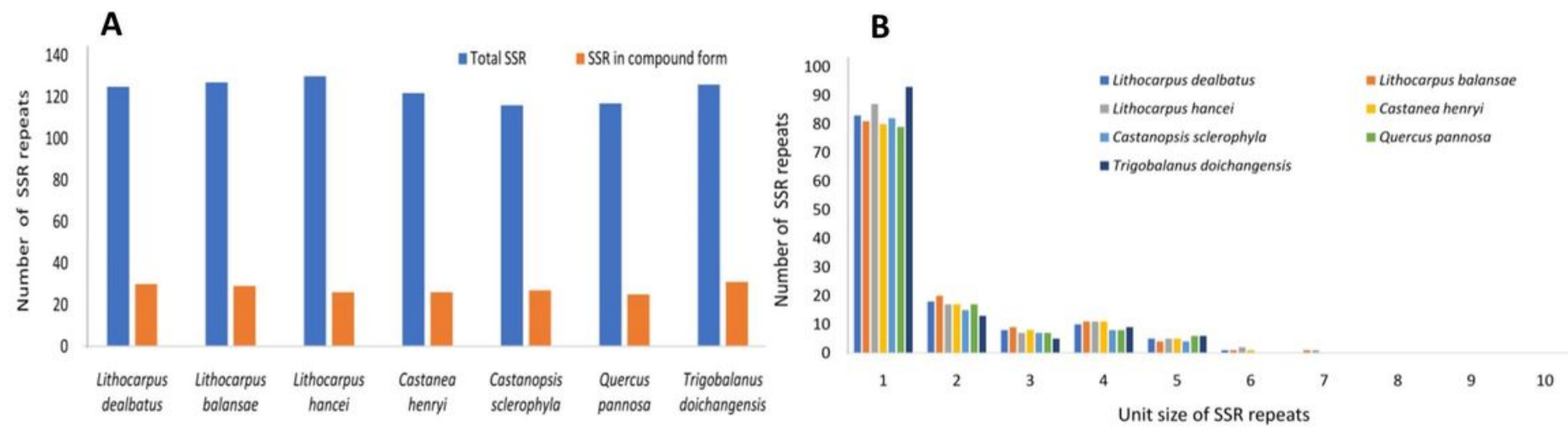

Species name

C

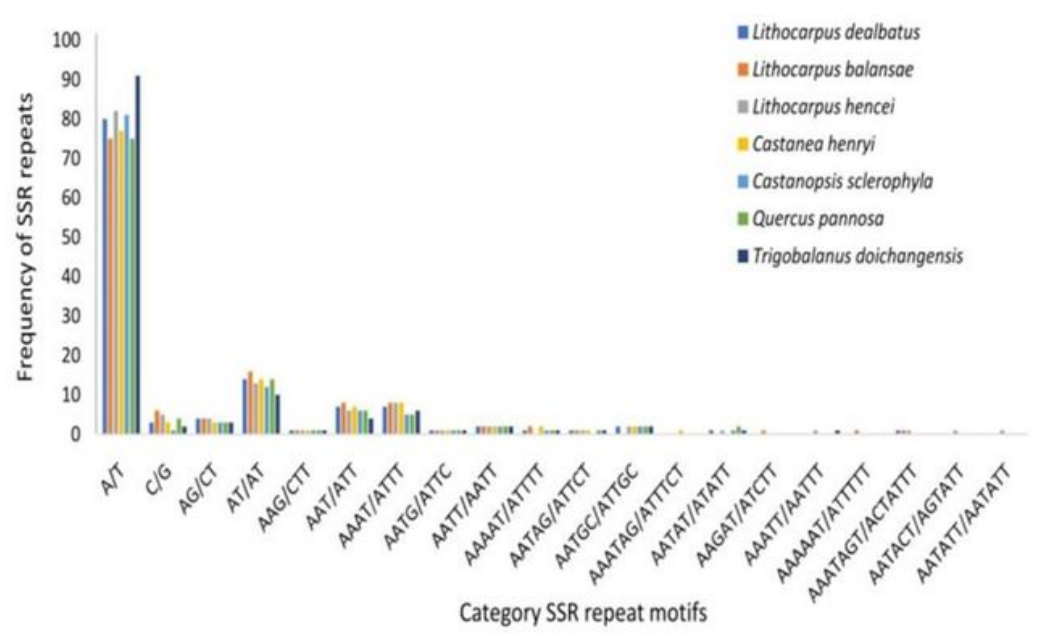

D

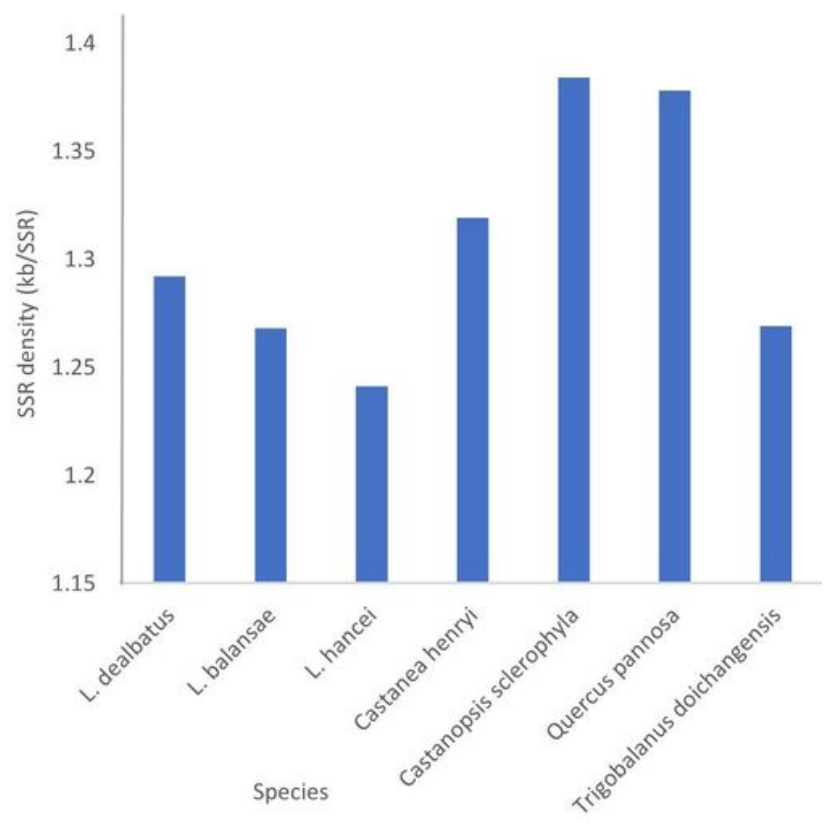

Figure 6

Category of SSRs in the compared Quercoideae genomes. A. Distribution of SSRs in simple and compound form, B. Representation of SSRs based on their unit size, C. Distribution of SSRs based upon the repeat motifs. 


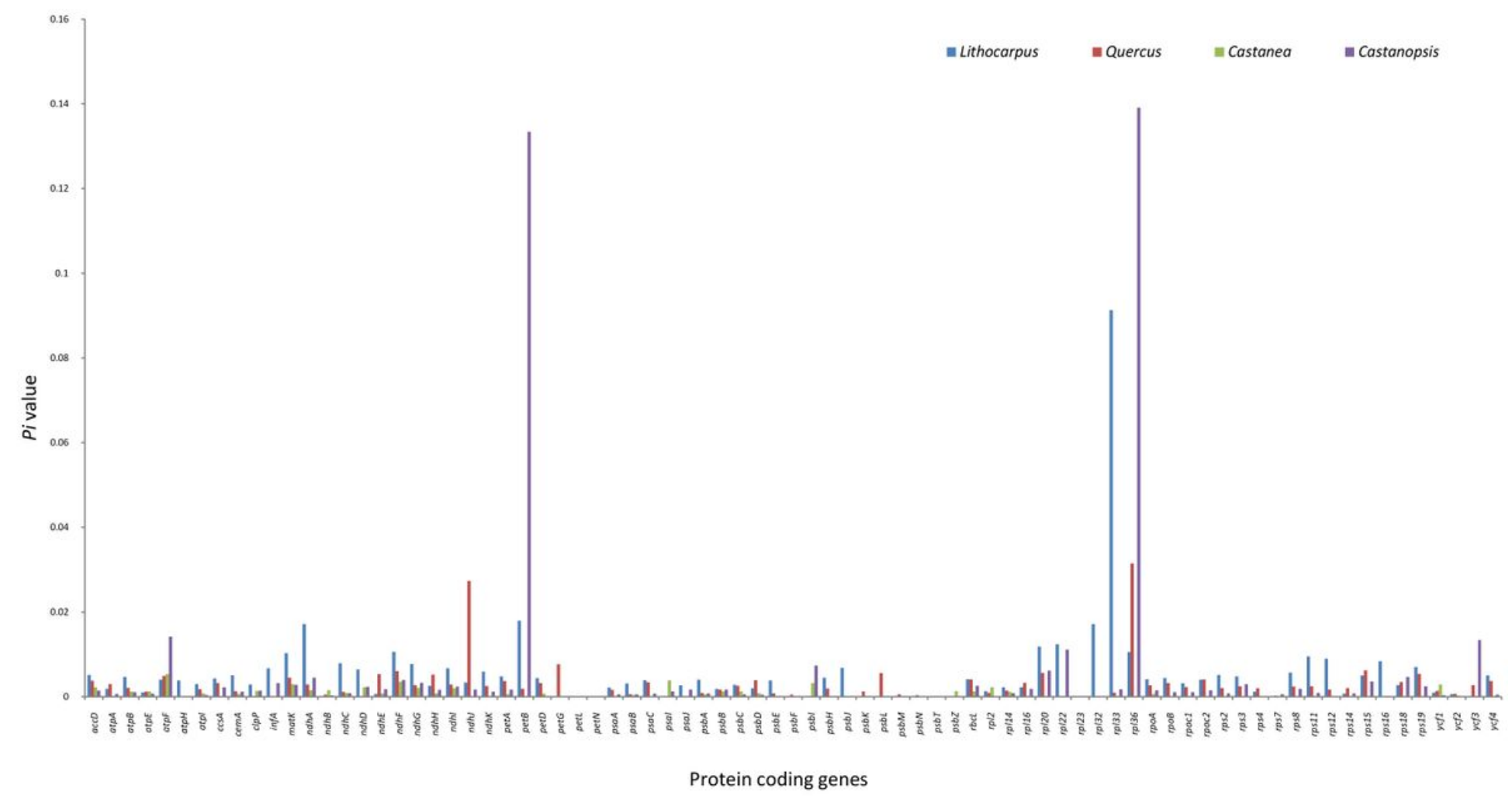

Figure 7

Comparison of the DNA diversity $(P I)$ values of protein-coding regions in Lithocarpus, Quercus, Castanea and Castanopsis

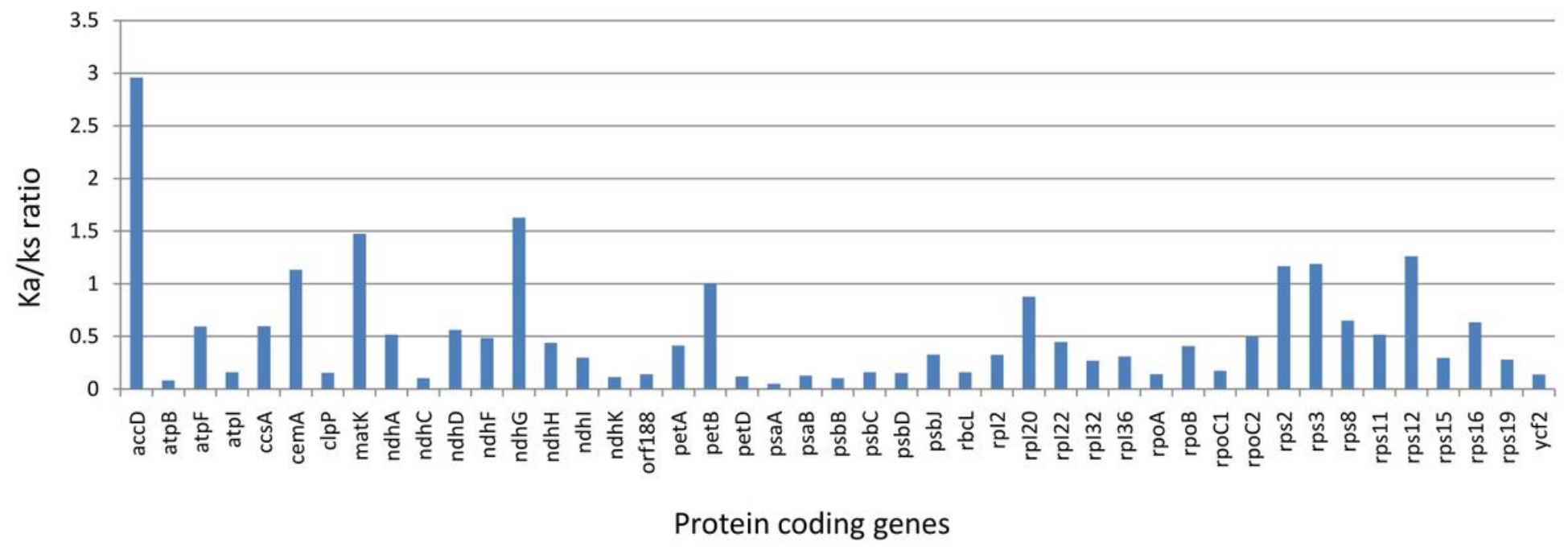

Figure 8

The comparative analysis of $\mathrm{Ka} / \mathrm{Ks}$ ratio from Lithocarpus chloroplast genomes for individual genes 


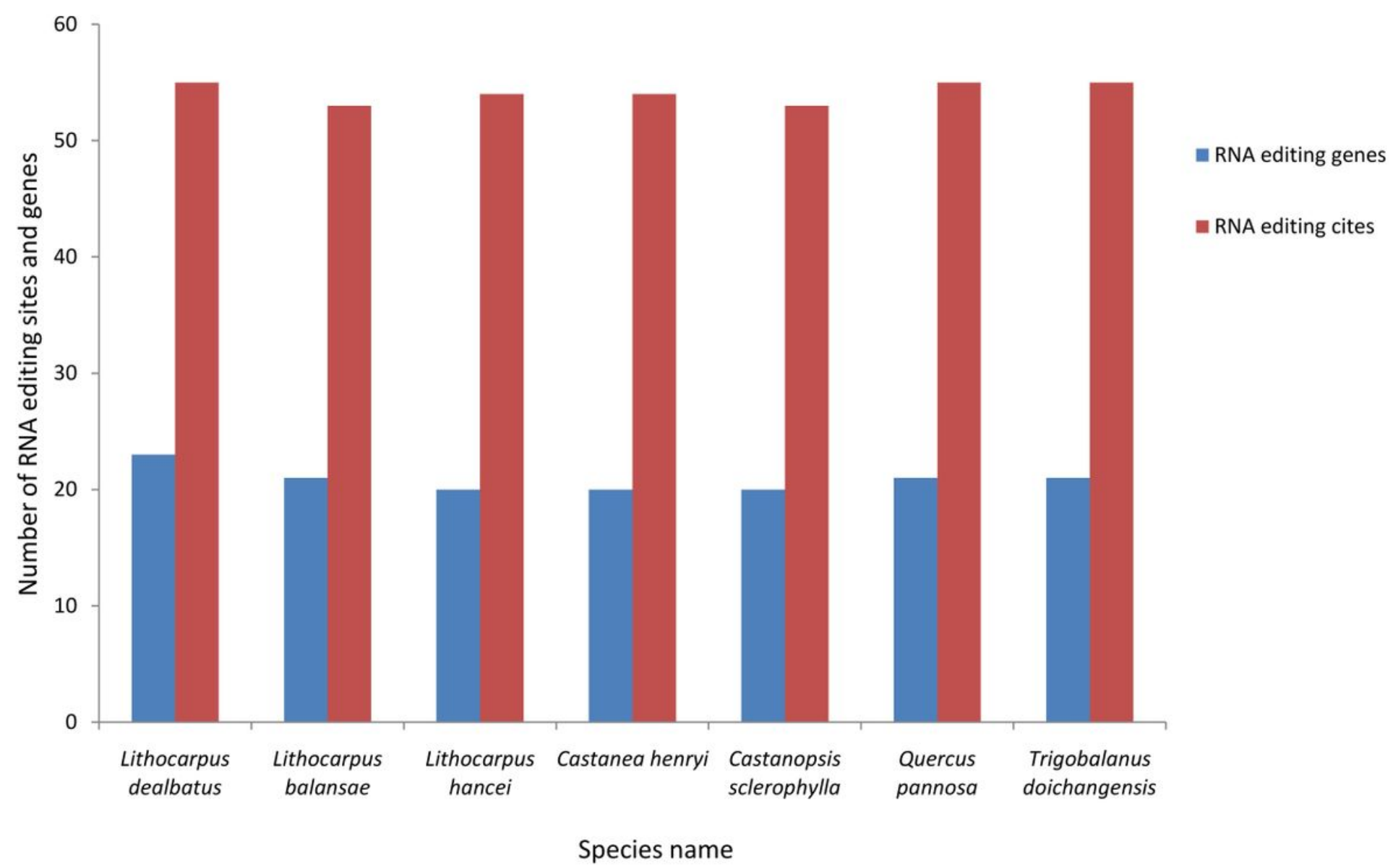

Figure 9

Distribution of RNA editing sites in genes across compared genomes 


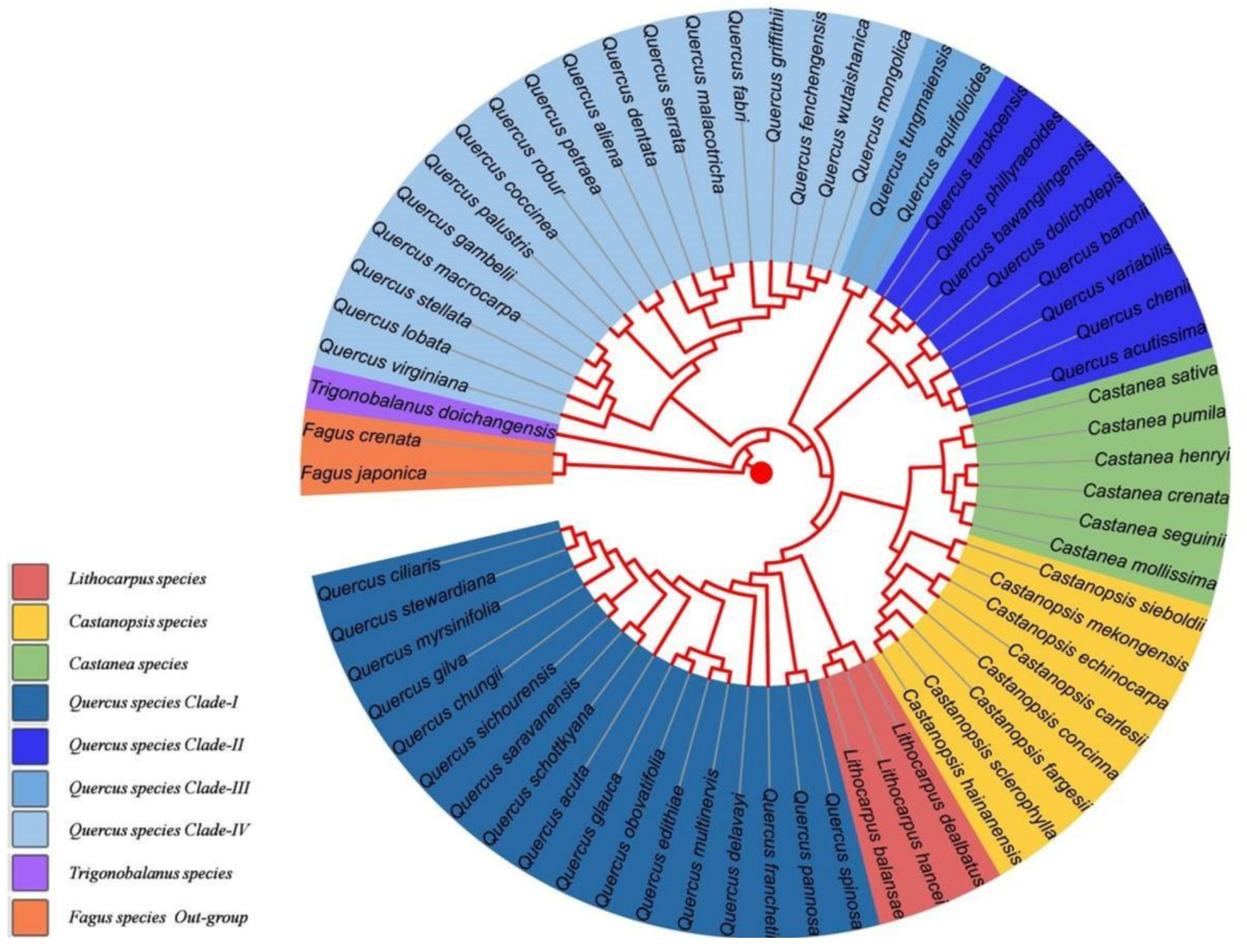

Figure 10

ML phylogenetic tree construction based on whole chloroplast genome Quercoideae species by keeping Fagus species as an out-group

\section{Supplementary Files}

This is a list of supplementary files associated with this preprint. Click to download.

- FigureS1.jpg

- FigureS2AD.jpg

- FigureS3.png

- Tables1.xlsx 